\title{
Application of the Land-Atmosphere Coupling Paradigm to the Operational Coupled Forecast System, Version 2 (CFSv2) $\mathscr{O}$
}

\author{
PAul A. Dirmeyer AND SubHadeep Halder \\ Center for Ocean-Land-Atmosphere Studies, George Mason University, Fairfax, Virginia
}

(Manuscript received 11 March 2016, in final form 13 October 2016)

\begin{abstract}
Retrospective forecasts from CFSv2 are evaluated in terms of three elements of land-atmosphere coupling at subseasonal to seasonal time scales: sensitivity of the atmosphere to variations in land surface states, the magnitude of variability of land states and fluxes, and the memory or persistence of land surface anomalies. The Northern Hemisphere spring and summer seasons are considered for the period 1982-2009. Ensembles are constructed from all available pairings of initial land and atmosphere/ocean states taken from the Climate Forecast System Reanalysis at the start of April, May, and June among the 28 years, so that the effect of initial land states on the evolving forecasts can be assessed. Finally, improvement and continuance of forecast skill derived from accurate land surface initialization is related to the three coupling elements. It is found that soil moisture memory is the most broadly important element for significant improvement of realistic land initialization on forecast skill. However, coupling strength manifested through the elements of sensitivity and variability are necessary to realize the potential predictability provided by memory of initial land surface anomalies. Even though there is clear responsiveness of surface heat fluxes, near-surface temperature, humidity, and daytime boundary layer development to variations in soil moisture over much of the globe, precipitation in CFSv2 is unresponsive. Failure to realize potential predictability from land surface states could be due to unfavorable atmospheric stability or circulation states; poor quality of what is considered realistic soil moisture analyses; and errors in the land surface model, atmospheric model, or their coupled interaction.
\end{abstract}

\section{Introduction}

Observationally based conjecture on the role of the land surface in seasonal climate dates back to at least the mid-twentieth century (e.g., Namias 1959, 1960) with a number of numerical modeling sensitivity studies beginning in the 1970s [see Dirmeyer and Shukla (1993) for a review]. Over the last 15-20 years, the importance of the land surface states to weather and climate has been thoroughly investigated with models. Much of the research that has contributed to the understanding of large-scale land-atmosphere coupling has taken place via the Global Land-Atmosphere System Study within the Global Energy and Water Exchanges project

Supplemental information related to this paper is available at the Journals Online website: http://dx.doi.org/10.1175/ JHM-D-16-0064.s1.

Corresponding author e-mail: Paul A. Dirmeyer, pdirmeye@ gmu.edu
(GLASS/GEWEX; van den Hurk et al. 2011). This has occurred in the context of multimodel experiments using both stand-alone land surface models (Dirmeyer et al. 1999, 2006) and coupled land-atmosphere models (Koster et al. 2006, 2011; Guo et al. 2006, 2012; Seneviratne et al. 2013; Berg et al. 2015; Lorenz et al. 2016) as well as many single-model studies (e.g., Berg et al. 2013; Roundy et al. 2014; Roundy and Wood 2015; Lorenz et al. 2015) and a smaller number of observationally based analyses (e.g., Ferguson and Wood 2011; Zhang and Klein 2013; Ford et al. 2015). Recently, single-column model investigations have been added to the list of coupled land-atmosphere studies (Best et al. 2013).

The effect of changes in the state of the land surface on weather and climate has typically been investigated through model sensitivity studies, where some aspects of the land surface or the connections between land and atmosphere in the model are altered, and the response of the climate system is determined through a comparison to a set of control (unaltered) simulations with the same model. The changes may be made to land surface 
states such as soil moisture (e.g., Koster et al. 2006), snow (e.g., Bamzai and Marx 2000), or vegetation (e.g., Betts et al. 2007); to surface properties such as albedo (e.g., Betts 2000) or roughness (e.g., Sud et al. 1988); or to fluxes that connect land and atmosphere such as surface heat fluxes (e.g., Koster et al. 2000), precipitation, or radiative fluxes (e.g., Dirmeyer and Zhao 2004). In each case, the impact of the specific change is isolated in that model. Multimodel investigations with similar perturbations across many models provide a more tenable result, less likely to be peculiar to a particular model's behavior (Tebaldi and Knutti 2007).

What sensitivity studies do is to intervene in the process chains that serve as feedback pathways from land to atmosphere in the physical climate system (Dirmeyer 2006; Betts 2009; Santanello et al. 2011, 2013; Dirmeyer et al. 2015). These chains pass primarily through the water and energy cycles, linking land surface states to surface fluxes, near-surface atmospheric states, and ultimately properties of the planetary boundary layer that affect buoyancy and convection, the likelihood of cloud formation and precipitation (e.g., Tawfik et al. 2015a).

A general paradigm is emerging that significant feedbacks of the land surface to the atmosphere exist when and where three key elements are present and sufficiently strong in the land-atmosphere system. The first necessary element is sensitivity: there must be a demonstrable response of one state or flux to variations in another-a bivariate relationship underpinned by real physical processes (e.g., Guo et al. 2006; Dirmeyer 2011; Lorenz et al. 2015). In this case, we are most concerned with connections that link the state of the atmosphere to a change in the land surface. This can be quantified in many ways, but the most common involve the demonstration of covariability between an aspect of the land surface and a corresponding aspect of the atmosphere. Such an approach is built on the assumption that a reasonable physical causality exists to generate the covariability, and furthermore that the causality is significant in the direction from land to atmosphere. In other words, it is expected that the change in the atmospheric property is the "effect" in the relationship. Modeling studies are especially useful in demonstrating such causality as one can specify the source of the change (e.g., by specifying an anomaly in soil moisture) and witness the response in the atmospheric component of the model system (e.g., Dirmeyer 2000; Koster et al. 2004; Hirsch et al. 2014). In nature, it is much more difficult to ascertain such feedback relationships, especially since there already exist strong causal relationships from atmosphere to land (precipitation necessarily increases soil moisture, excessive heat promotes greater potential evaporation, etc.).
A specific example of sensitivity quantified by covariability is the relationship between soil moisture and latent heat flux/evapotranspiration (Dirmeyer et al. 2009). It is fairly straightforward to calculate the correlation between these two quantities, using daily means from observations at a flux tower with collocated soil moisture measurements, or from land surface model output. A significant positive correlation between soil moisture and evapotranspiration (ET) is an indicator that a land surface feedback is at play, that is, that soil moisture is a factor in controlling evaporation. In this case, an increase (decrease) in soil moisture results in an increase (decrease) in ET, meaning that it is not a lack of energy but a lack of water in the soil that is restricting the rate of ET. If the two quantities are negatively correlated, it would indicate that ET is the driver and soil moisture is responding to ET-an increase in ET draws down soil moisture while a lack of ET allows soil moisture to remain elevated. In this situation, it would be the other controls on ET such as available energy, dryness of the lower atmosphere, or strength of the wind that are ultimately controlling the link with soil moisture, and the state of the soil moisture itself is not governing the surface fluxes.

The second element for significant land-atmosphere feedback is variability. Strong sensitivity is of scant consequence if the forcing component in the feedback does not vary much in time or manifest in large anomalies (Guo et al. 2006). A clear example of sensitivity without variability exists in the world's warm deserts. In these locations, energy to supply ET is abundant, but water is lacking. Therefore, a strong positive correlation between soil moisture and ET is found in these locations. However, in deserts rain rarely occurs, so soil moisture is seldom available for evaporation. Thus, although there is ample sensitivity of surface fluxes to soil moisture, the latter's absence in all but rare instances means that its overall variance is small, and it seldom has an impact on the overlying atmosphere. Locations where soil moisture varies appreciably from day to day and week to week have, in the presence of sensitivity, greater feedbacks to the atmosphere via the water cycle than perpetually dry (or wet) locations. The elements of sensitivity and variability are often combined into a single metric of coupling (e.g., Guo et al. 2006; Dirmeyer 2011; Lorenz et al. 2015).

The third element is the persistence of anomalies or "memory" (Delworth and Manabe 1989; Koster and Suarez 2001). The longer a land surface anomaly endures in a region that also has significant sensitivity and variability, the greater the cumulative effect on the atmosphere can be. Several factors affect land surface memory. Properties of the land surface, particularly soil 
texture, soil and rooting depths, and the general hydrologic characteristics of an area affect the persistence of soil moisture anomalies. The atmosphere is also a major determinant of land surface memory. Baroclinic regions with frequent synoptic-scale storm passages tend to have relative low memory as the periodic storms inhibit the lifetime of soil moisture anomalies except when induced by persistent large-scale atmospheric circulation anomalies. Downslope regions in mid- and high latitudes that experience alternating cold and foehn winds have difficulty maintaining positive snow cover anomalies.

Modeling studies and validation efforts have led to growing confidence in the actuality of the land surface's sway over aspects of weather and climate (e.g., Beljaars et al. 1996; Dirmeyer 2000; Koster et al. 2004, 2011; Fischer et al. 2007). However, a systematic assessment of coupled land-atmosphere signatures in an operational forecast model in the context of sensitivity, variability, and memory has not been undertaken. In this paper, we examine the operational forecast model of NOAA/ NCEP (CFSv2) to determine its characteristics in each of the three elements of land-atmosphere coupling. This model has been investigated in the context of its existing Climate Forecast System Reanalysis (CFSR) and Reforecast (CFSRR; Saha et al. 2010) dataset for landatmosphere feedbacks (Dirmeyer 2013; Roundy et al. 2014; Roundy and Wood 2015). In a companion study (Dirmeyer and Halder 2016), the effect of land surface initialization on the first hours and days of forecasts is investigated. In this study, we assess the model's response to the initialization of land surface states in terms of changes in forecast skill, and whether they can be attributed to the elements described above.

Section 2 describes the coupled land-atmosphereocean model, retrospective forecast experiments, and validation datasets. The properties of sensitivity, variability, and memory are quantified in sections 3,4 , and 5 , respectively. Their separate and aggregate association with forecast skill is examined in section 6. Section 7 presents conclusions.

\section{Model, experiments, and validation data}

CFSv2 is the global model used in this study (Saha et al. 2014). The coupled model consists of the Global Forecast System, version 2 (GFSv2), atmospheric model coupled to the Noah land surface model, version 2.7.1 (Ek et al. 2003), and to the Modular Ocean Model, version 4 (MOM4; Griffies et al. 2004).

The atmospheric horizontal resolution for hindcast experiments is approximately $0.9^{\circ}$ (T126 spectral resolution) and the ocean has a horizontal resolution of $12^{\circ}$, increasing to $1 / 4^{\circ}$ in the meridional dimension near the equator. GFSv2 has 64 sigma-pressure hybrid levels extending up to $0.26 \mathrm{hPa}$ and MOM4 has 40 levels down to $4740 \mathrm{~m}$. Sea ice is predicted using a modified version of the GFDL Sea Ice Simulator (cf. Saha et al. 2010). Noah has four soil layers extending to a depth of $2 \mathrm{~m}$ and calculates the surface energy and water budgets and estimates the transpiration component of evapotranspiration based on plant water stresses. Soil and vegetation characteristics are prescribed to vary spatially across the globe, and a climatological seasonal cycle of vegetation fraction is imposed but leaf area index is fixed (Meng et al. 2012). Snow is treated as a single thermodynamic slab.

We focus on the boreal warm season because of the extensive global land area that is in a water-limited surface flux regime and thus more sensitive to landatmosphere feedbacks (e.g., Song et al. 2016). Ensemble retrospective forecast simulations are initialized at 0000 UTC on the first day of April, May, and June and continue until 0000 UTC 1 October for each of the 28 years spanning 1982-2009. For each initial date, the baseline ensemble member (control run) is initialized from the NCEP CFSR (Saha et al. 2010) for that date. The initialization approach for the control runs is essentially the same as the reforecasts from CFSRR except the initialization dates are at the start of months. The other 27 ensemble members are initialized with identical atmosphere, sea ice, and ocean states as in the baseline simulation, but initial land states are taken from each of the other 27 years (cf. Schlosser and Milly 2002). The result for each forecast start date (1 April, 1 May, and 1 June) is a matrix of $28 \times 28=784$ forecasts with each possible combination of initial atmosphere, ocean, and sea ice states versus initial land from CFSR. Model output is every $6 \mathrm{~h}$ and averaged to daily means (partitioned at 0000 UTC) for the analyses presented here.

The atmospheric model GFSv2 used to generate CFSR has a higher spatial resolution $(\mathrm{T} 382, \sim 38 \mathrm{~km})$ than our experimental configuration, so initial states are interpolated to the lower resolution. Land states used for initialization of our reforecast experiments include soil water and ice content, soil and skin temperatures, snow mass, and canopy water content that are based on the CFSR surface analysis. To ensure that biases in model parameterization schemes that may lead to systematic errors in the precipitation statistics are prevented from affecting the soil moisture states, observed precipitation and snow depth analyses were used in the CFSR GLDAS Land Information System (LIS) framework, which is derived from the NASA version of LIS (Peters-Lidard et al. 2007). The land surface analysis produced, also using Noah to maintain consistency of 
model physics, replaced the land surface state variables of CFSR every day at 0000 UTC from the previous $24 \mathrm{~h}$ GLDAS simulation. In following this methodology, the land surface model is said to be "semi-coupled" to the atmosphere in CFSR. The GLDAS LIS uses a similar land-sea mask, terrain height, soil and vegetation data, and related parameters as in the CFSR at the same resolution.

To address spinup issues over land, the initial conditions for the GLDAS LIS simulation were derived by averaging GFSv2 daily land surface states for the years 2006 and 2007 along with additional spinup for one year. The offline simulation used atmospheric forcing from the Global Data Assimilation System (GDAS) and a global observed precipitation analysis mentioned above, optimally blended with the background 6-hourly precipitation generated by the GDAS. The global daily precipitation analysis is generated by merging of the satellite and gauge-based CMAP (Xie and Arkin 1997) pentad (5 day) data and the CPC Unified Gauge-Based Analysis of Global Daily Precipitation that follows the method of Xie et al. (2007). At high latitudes model precipitation from the Climate Data Assimilation System (CDAS) is included, transitioning to the gauge and satellite observations at lower latitudes.

The daily snow water equivalent depth analysis was generated from the snow depth analysis (SNODEP) of the Air Force Weather Agency (Kopp and Kiess 1996) and the NESDIS Interactive Multisensor Snow and Ice Mapping System (IMS; Helfrich et al. 2007). The data were horizontally interpolated conserving total water volume, following Accadia et al. (2003). After February 1997, the IMS data were used as they had better quality control than the SNODEP data. The snow depth and liquid water equivalent from the coupled model were updated every day at 0000 UTC by comparison of the forecast guess field and the daily analysis, for maintaining a smooth evolution of the snowpack. Like precipitation, the daily snow analysis at 0000 UTC was also used to update the snow states in the GLDAS LIS. However, there are two important differences between the Noah land surface model used to generate the CFSR and the GLDAS LIS, and CFSv2 used for our reforecasts. To ameliorate a low-level warm bias over the midlatitudes found while performing CFSv2 reforecasts (Saha et al. 2014), vegetation parameters in CFSv2/ Noah were tuned and rooting depths extended into the lowest soil layer so as to increase surface evapotranspiration and hence reduce temperatures (cf. Roundy et al. 2014). Additionally, the runoff parameters of the land surface model were adjusted to correct a low bias in runoff.
In addition to changes in Noah, there are other differences in the GFSv2 used in CFSR and CFSv2 (Saha et al. 2014). While CFSR used enthalpy as a prognostic variable, virtual temperature was used in CFSv2. To reduce the excessive formation of low marine stratus clouds leading to cold equatorial SSTs in CFSR (Saha et al. 2010; Sun et al. 2010), earlier cloud physics modifications made to GFSv2 were turned off. A cumulusconvection-based gravity wave drag parameterization (Chun and Baik 1998) was also introduced in CFSv2. Apart from these, a new Monte Carlo independent column approximation (McICA) scheme (Barker et al. 2002; Pincus et al. 2003) was incorporated to better resolve variability of layered clouds in a grid and cloudradiation interactions along with the Rapid Radiative Transfer Model (RRTM; Mlawer et al. 1997; Iacono et al. 2000; Clough et al. 2005) used in CFSR.

The sea surface temperature (SST) analysis for the ocean uses two daily SST analyses at $1 / 4^{\circ}$ developed using an optimum interpolation scheme. The first is AVHRRonly SST data (from November 1981 through May 2002) and the second is combined AMSR and AVHRR SST data from June 2002 onward (Reynolds et al. 2007). Because of lack of observed sea ice thickness and transport data during the entire period of CFSR, only sea ice concentration data are prescribed as an initial condition. Sea ice concentrations are derived from the Cavalieri et al. (1996, 2007) dataset through 1996, after which the NCEP operational ice analysis (Grumbine 1996) is used. A detailed description of the preparation of CFSR may be found in Saha et al. (2010). Retrospective forecast validation in this study is performed against the CFSR dataset. Interannual temporal anomaly correlation coefficients (ACCs) of pentad mean or monthly mean forecasts at increasing lead times from initialization are calculated for each set of forecasts with the same initialization date. For the cases with realistic land surface initialization, the single member for each initial month and forecast year is used; otherwise, ensemble means are considered.

\section{Sensitivity}

The first element of land-atmosphere coupling we examine in CFSv2 is the sensitivity of surface latent and sensible heat fluxes to soil moisture state. We look at two related statistics: 1) contemporaneous Pearson productmoment correlation between daily fluxes and moisture in the top $10 \mathrm{~cm}$ of soil and 2) the slope of the best fit linear regression of fluxes as a function of soil moisture. In each case, statistics are aggregated by month (actually 30 days for every month) for a period spanning boreal spring and summer (April-August) using all daily means 
from all forecasts in the month. For April, each model grid box over land includes $28 \times 28 \times 30=23520$ days in the calculations. For May, forecasts initialized on 1 April and 1 May are included, so the sample is doubled. For June the June forecasts are added, tripling the sample size. The July and August estimates step back down in sample size as data beyond the third month of any forecasts are not used in these estimates. This necessarily mixes data from various forecast lead times, both within and between months, but is an unavoidable consequence of the experimental setup. We have compared results shown in this paper to calculations using only the first or third months of forecasts and find the fluctuations to be small. The only noticeable area of variation appears to be over northeastern Asia in June (not shown), associated with the model snowmelt biases. Given that this is not a region of strong land-atmosphere coupling, we conclude that our compositing approach does not significantly affect the results. The sample sizes are so large that essentially all colored areas in maps are significant at better than $95 \%$ confidence.

As alluded to above, there is growing drift in the forecasts such that the climatology of June, for instance, is not identical to the 1-month forecast initialized on 1 June and the 3-month forecast initialized on 1 April. The most prevalent differences are related to systematic errors in the simulation of snowpack and a delayed timing of snowmelt that affect a number of variables on the edge of the retreating Northern Hemisphere snow field including soil moisture and temperature (cf. Dirmeyer 2013).

Associations between correlation, slope of the linear regression, and variances among soil moisture and surface fluxes have been described in terms of the terrestrial coupling index (Dirmeyer 2011; Dirmeyer et al. 2012). Correlations between $0-10-\mathrm{cm}$ soil moisture and both latent and sensible heat fluxes are shown in Fig. S1 in the supplemental material; Fig. S2 in the supplemental material shows the sensitivity as the slope of the linear regression $[d($ flux $) / d$ (soil moisture)]. These metrics are not novel and have been shown for a variety of models in other studies; CFSv2 results in Figs. S1 and S2 are comparable to other studies and are described in the supplemental material. We will note here that in Fig. S1 negative correlations exist in agricultural areas as a consequence of the extension of root depths into the lowest soil layer of Noah, which results in excessive humidity, cloud, and shallow boundary layers, particularly over the Great Plains (Roundy et al. 2014; Dirmeyer and Tawfik 2014).

Sensitivity can vary with soil moisture itself (e.g., Koster et al. 2009; Roundy et al. 2014). We expand upon the sensitivity metrics by quantifying not just where but when (in terms of soil moisture state) the atmosphere is sensitive to fluctuations in the land state. At each model grid box for each month we find the largest and smallest values of daily volumetric soil moisture and divide that range into three bins of equal width: a dry bin, a moderate bin, and a wet bin. We then recalculated correlations separately within each bin. Figure 1 shows when and where there are correlations exceeding \pm 0.4 in each bin, suggestive of strong terrestrial coupling over North America (global versions of all North America maps are provided in the supplemental material, e.g., Fig. S3 in this case). In all calculations involving soil moisture, land regions lacking intraensemble variability of $40-100-\mathrm{cm}$ soil moisture (intraensemble variance $=0$ on day 30 of the forecast) are masked out, predominantly affecting the most arid desert points and areas of frozen ground.

For latent heat flux, the correlations are large across the whole range of soil moisture only over the driest regions. The range of sensitivity contracts to the dry and middle thirds in areas north and east of the desert Southwest, expanding further from spring through summer. Beyond that in July and August is an area covering most of the Great Plains where only relatively dry soils contribute to large correlations. There is also an area of dry-only sensitivity that moves north from the central Rocky Mountains in April to the Arctic coast in June and July, following the melting snow. Very few locations show significant correlations biased toward the wet end of the soil moisture spectrum, and they are frequently individual grid boxes suggesting they may be the result of computational noise rather than coherent regions of systematic characteristics.

For correlations of sensible heat flux with soil moisture (Fig. 1, right) there is often a tendency for strong coupling on the wet side of the soil moisture range (shades of blue), although over much of Texas and Mexico there is broad sensitivity in summer. An interesting exception appears over the Great Plains in July and August, where sensitivity is also confined to the dry range, corresponding well with Fig. 1 (left). For both fluxes, summer correlations with soil moisture are generally low over the eastern parts of Canada and the United States, except near the Gulf Coast. It should be noted that bins specified in this way contain very different numbers of points, as soil moisture is rarely distributed evenly across its range (see Fig. S4 in the supplemental material).

The atmospheric leg can be examined in many ways. We consider the surface flux variations that are the consequences of land variability (the terrestrial leg) as drivers or forcings of the atmospheric leg. Through the energy cycle, one of the most direct connections is between surface sensible heat flux and the depth of the 


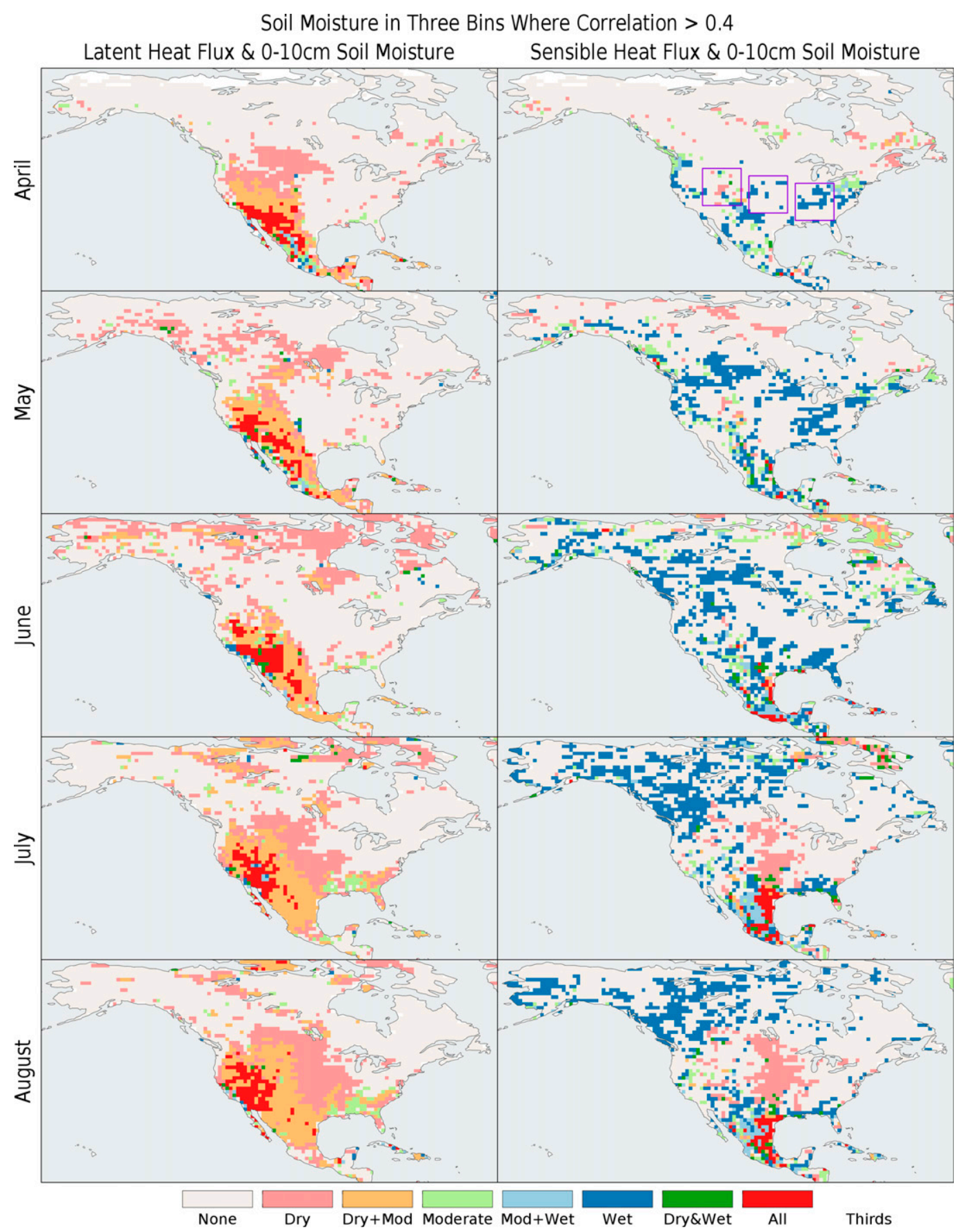

FIG. 1. Soil moisture bins over North America where the correlations of soil moisture with (left) latent heat flux are greater than 0.4 or (right) sensible heat flux are less than -0.4. "Dry," "moderate," and "wet" refer to soil moisture state where the range of simulated soil moisture is divided into three bins of equal span.

daytime planetary boundary layer (Betts et al. 1996). The evolution of this linkage from April through August is shown in Fig. 2 (left) (globally in Fig. S5 in the supplemental material). Strong positive correlations exist over the tropics, mountainous areas, and snow-free higher latitudes. It is easier to explain the areas that do not have strong positive correlations. Over snow the correlations are negative because deeper boundary layers accompany warm advection and snowmelt, which is a negative sensible heat flux and a consequence of the 


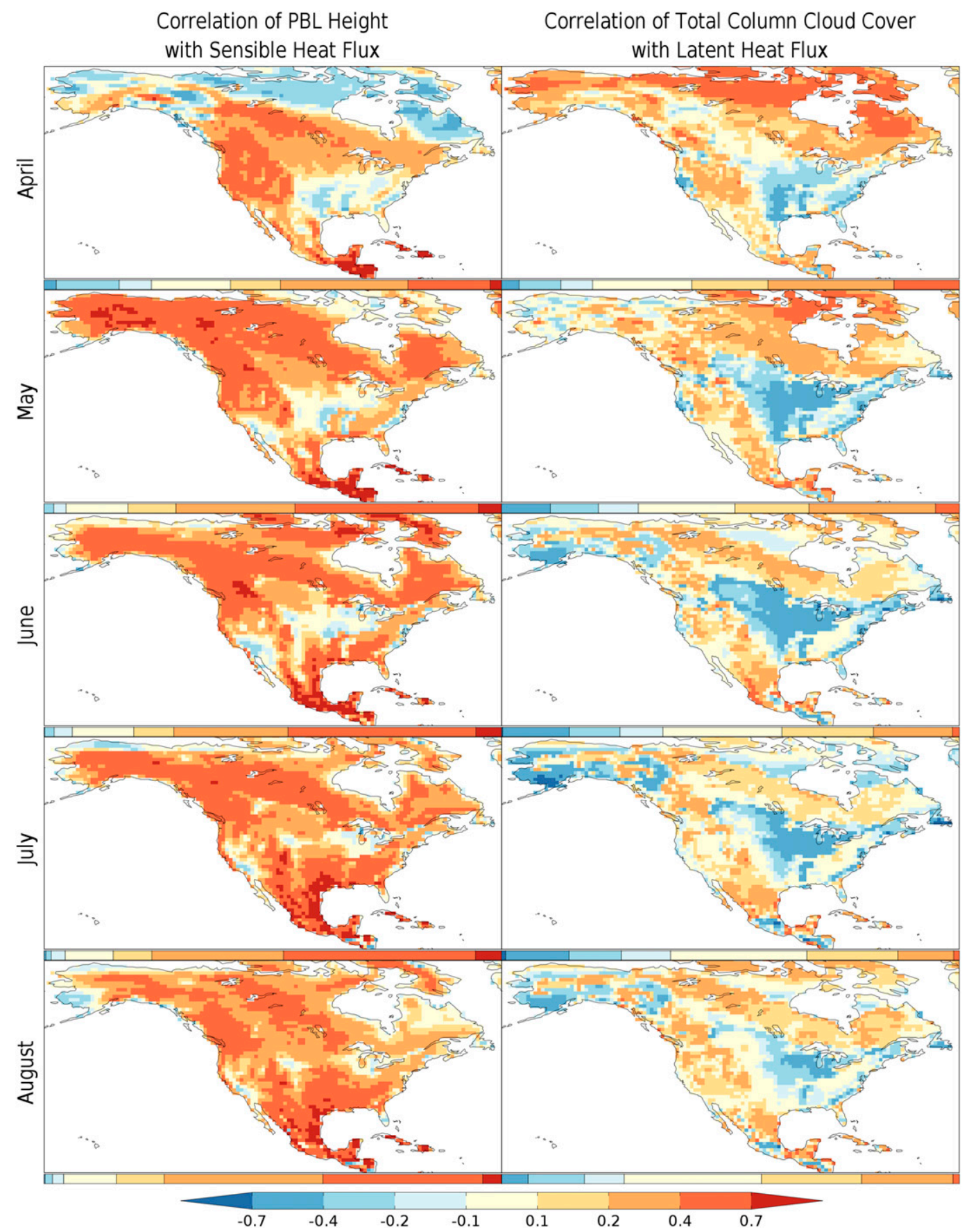

FIG. 2. Correlations between the indicated terms for the atmospheric leg of land-atmosphere coupling. The colored bars below each panel are proportional in width to the area of the map in each category.

warm advection. Weak or negative correlations over much of the agricultural belt of central North America are another symptom of the extended rooting depths in Noah mentioned previously.

The agricultural footprint in central North America is very clear in the correlation between surface latent heat flux and total column cloud cover in Fig. 2 (right). Those regions exhibit considerable negative correlations, suggesting that over those regions increasing (decreasing) cloud cover limits (increases) net radiation and reduces (increases) evaporation. This is the signature of a wellwatered regime, like exists in rainy areas of the tropics 
and coastal high-latitude forests. Strong positive correlations exist mainly in three regimes: semiarid regions where moisture is fairly limited but energy is plentiful, in baroclinic regions (e.g., much of Canada), and over snow and ice. In semiarid regions, it cannot be told without sensitivity studies to what degree the positive correlations arise because increased evaporation enables more cloudiness or that cloudiness is an indicator of precipitation that supplies moisture for evaporation that would not normally be present. Over baroclinic regions and snow the linkage is clearer: cold dry air is clear but incapable of accepting much moisture from snow sublimation, while warmer air can drive strong sublimation and support low cloud formation. Similar patterns are seen for the correlation between latent heat flux and boundary layer cloud cover (not shown) except that the tropical regions become positively correlated, suggesting the presence of the "wet soil advantage" regime (Findell and Eltahir 2003a,b; Ferguson et al. 2012). Correlations of surface heat fluxes with convective available potential energy and convective cloud cover are almost ubiquitously positive for latent heat flux and negative for sensible heat flux (not shown), with the agricultural regions again standing out as an exception in latent heat flux linkages.

\section{Variability}

The standard deviations of daily soil moisture in each of the top two layers of Noah for April-August over North America are shown in Fig. 3 and globally in Fig. S6 in the supplemental material. The largest variability is associated with the timing of snowmelt in bands along the edge of the retreating snowpack from April to June. Variability in the onset of the North American monsoon manifests as a dark shaded region along the Pacific coast of Central America and Mexico in May and June. Fairly stationary regions of large soil moisture standard deviation exist over central North America. Florida has high values during spring that migrate north along the Atlantic coast in summer. The Appalachian Mountains and Piedmont maintain low soil moisture variability throughout the period.

Variability for latent and sensible heat fluxes is presented in Fig. S7 and is described in the supplemental material. The coupling index defined by Guo et al. (2006) and Dirmeyer (2011) combines measures of sensitivity and variability into a single metric. The index can be expressed as $\operatorname{cov}(F, R) / \sqrt{\operatorname{var}(F)}$, where $F$ and $R$ stand for the forcing and response variables, the response being downstream from the forcing assuming cause-effect relationships in the process chain of Santanello et al. (2011), calculated across all days in the sample. The index tells how much the response variable can be expected to vary for a one-standard-deviation change in the forcing variable.

Terrestrial coupling indices linking surface soil moisture (forcing) to latent and sensible heat fluxes (responses) are presented in Fig. 4 for North America and Fig. S8 in the supplemental material for the globe. The sign of the index for sensible heat flux has been reversed (anticorrelations are positive) for clarity and comparison. The large positive values when latent heat flux is considered (Fig. 4, left) have been equated with coupling hot spots (e.g., Dirmeyer 2011; Dirmeyer et al. 2013). We see those regions migrate from Mexico and the southern Great Plains during spring into all of the Great Plains and the southeastern United States late in summer. There are also spots across the Intermountain West. Coupling via sensible heat flux again reflects the snowmelt front but also the advancing monsoon at lower latitudes. No regions show the opposite sign of terrestrial coupling index between soil moisture and sensible heat $\left(<-5 \mathrm{~W} \mathrm{~m}^{-2}\right)$ indicative of a positive correlation.

The connection to the atmosphere is shown by atmospheric coupling indices in Fig. 5 and Fig. S9 in the supplemental material. The link between surface sensible heat flux and boundary layer height is strong in areas where the correlations were large in Fig. 2, notably in lower latitudes, but also across snowmelt regions at higher latitudes where the sensitivity is lower but variability is greater. The role of variability to enhance coupling where sensitivities are moderate is evident for the linkage between latent heat flux and cloud cover (Fig. 5, right). In June-August, positive values over the southern Great Plains and western mountains suggest that land and atmosphere in these regions are strongly coupled through the water cycle as well as the energy cycle in CFS. The "hole" over the agricultural regions of the Ohio, Mississippi, and Missouri River valleys in this model is conspicuous.

\section{Soil moisture memory}

The lagged autocorrelation of daily soil moisture decreases exponentially with lag because soil moisture behaves very much like a first-order Markov process (Schlosser and Milly 2002), meaning that soil moisture memory, defined as the lag at which the log of the autocorrelation drops to -1 , can be estimated from a curve fit through estimates over a small number of lags (Dirmeyer et al. 2016). Figure 6 presents estimates of this element by month for each of the top two layers of the Noah model in CFSv2 (globally in Fig. S10 in the supplemental material). Memory is shorter for the 


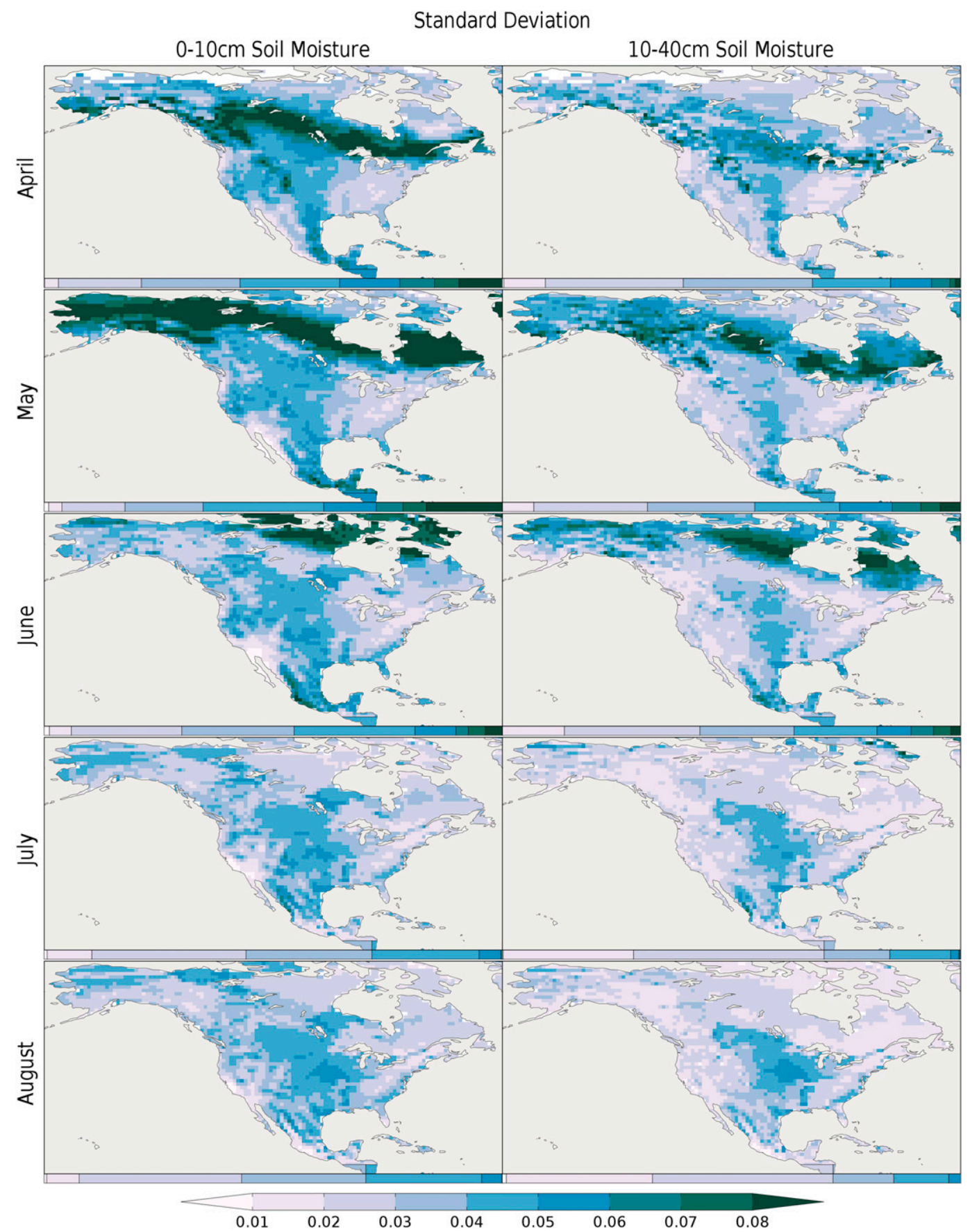

FIG. 3. The std dev of volumetric soil moisture (dimensionless) in the top two layers of the soil (areas of very low soil moisture variability are masked out).

surface layer than deeper layers and is longer than 12 months in arid regions and under snowpack. It is very short in rainy and humid regions. Over North America, memory peaks for surface soil moisture in May-June in the western United States but during July-August over the Mississippi River valley. There is a shifting region of low memory from the southeastern United States to
Quebec across the months. A key feature seen in North America and globally (Fig. S10 in the supplemental material) is that some of the classical hot spots of Koster et al. (2004) also tend to have relatively low memory. This is clearly evident for the Great Plains, where there is actually a local minimum in memory during July and August. 


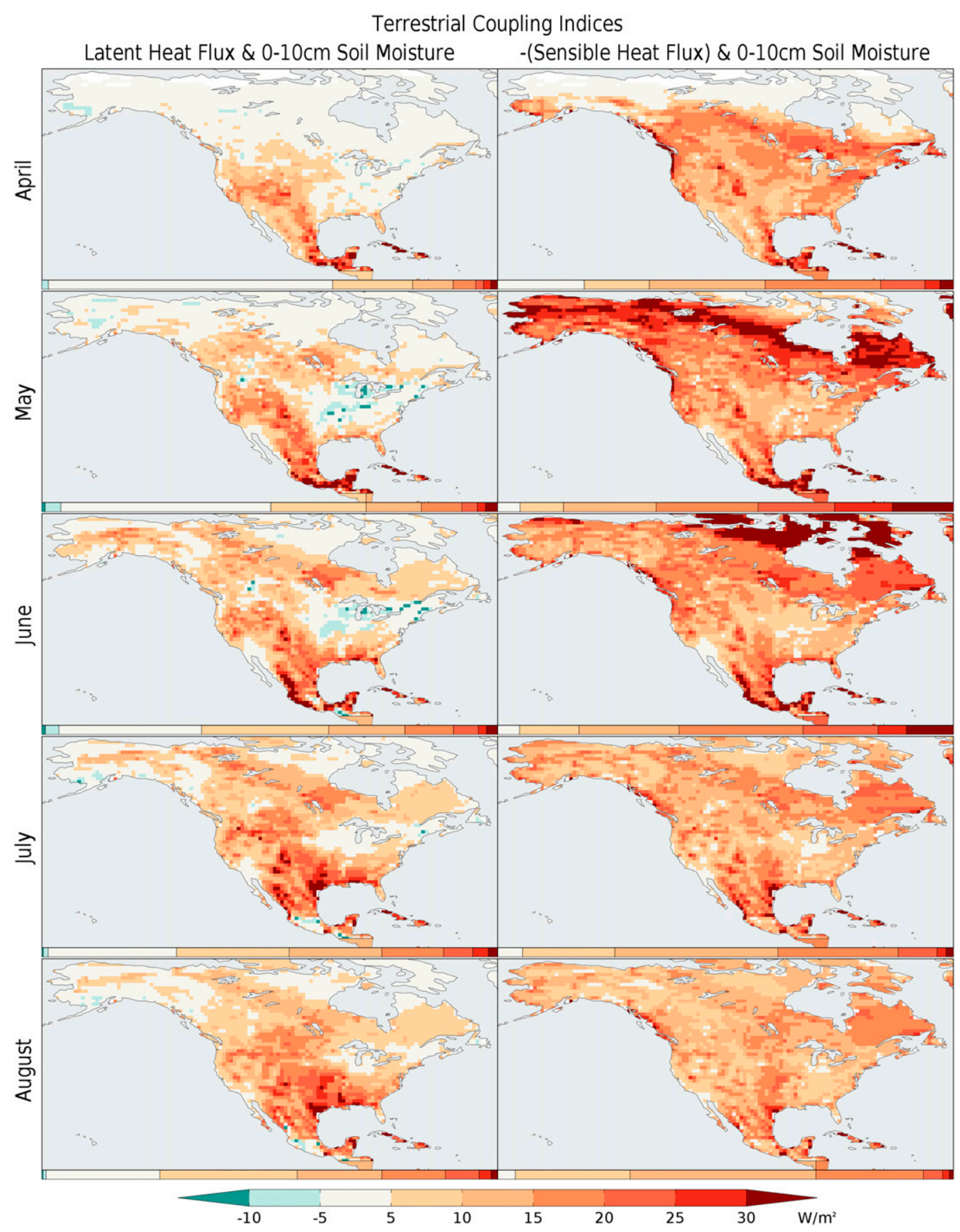

FIG. 4. As in Fig. 3, but for terrestrial coupling indices between (left) soil moisture and latent heat flux and (right) negative of sensible heat flux.

Results from sections 3 to 5 are integrated in Table 1. Area averages are calculated for the indicated quantities, which are represented in Fig. S1 in the supplemental material and Figs. 2-6. Averages over three areas are considered as outlined in Fig. 1 (top right): a western box spanning $35^{\circ}-45^{\circ} \mathrm{N}, 116^{\circ}-106^{\circ} \mathrm{W}$; a central box encompassing $33^{\circ}-43^{\circ} \mathrm{N}, 104^{\circ}-94^{\circ} \mathrm{W}$; and an eastern box over $31^{\circ}-41^{\circ} \mathrm{N}, 92^{\circ}-82^{\circ} \mathrm{W}$. Correlations between soil moisture and surface fluxes are strongest over the western United States. Latent heat flux correlations become large after the transition from spring to summer across the central and eastern areas but are fairly large for sensible heat flux (in the absolute sense) throughout the period. The evolution of correlations between soil 


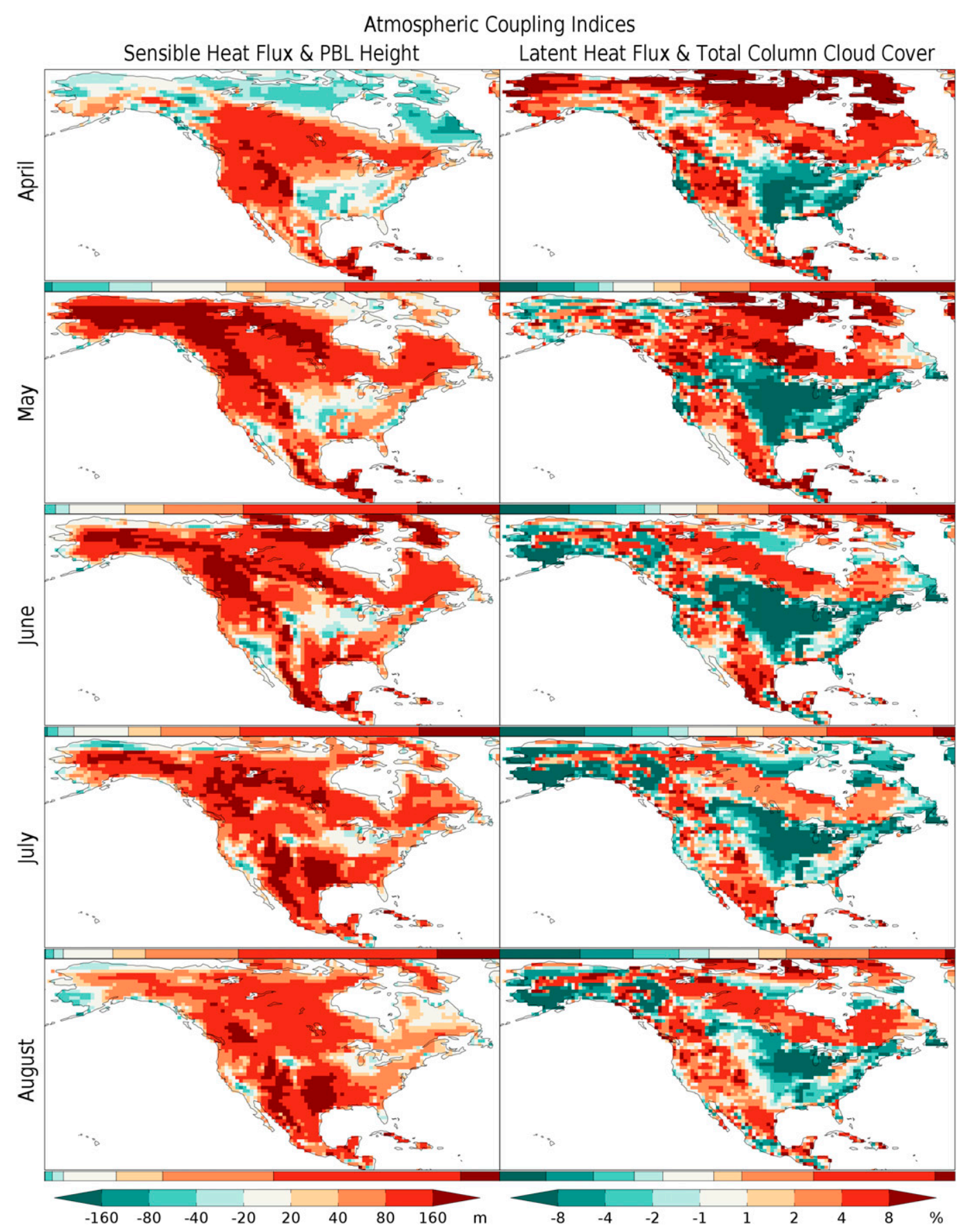

FIG. 5. As in Fig. 2, but for atmospheric coupling indices described by the quantities indicated.

moisture and latent heat flux are mirrored by those between sensible heat flux and PBL depth.

Temporal soil moisture variability is largest over the central United States, except during April when values in the west are highest. Naturally, the coupling indices reflect a combination of the correlations and variances, meaning they are generally a bit stronger over the central United States than the correlations, and a bit weaker over the west. Soil moisture memory is always greatest in the west during these months, generally declining toward the east.

\section{Connections to forecast skill}

Can we see the signature of the elements of sensitivity, variability, and memory of land-atmosphere coupling in 


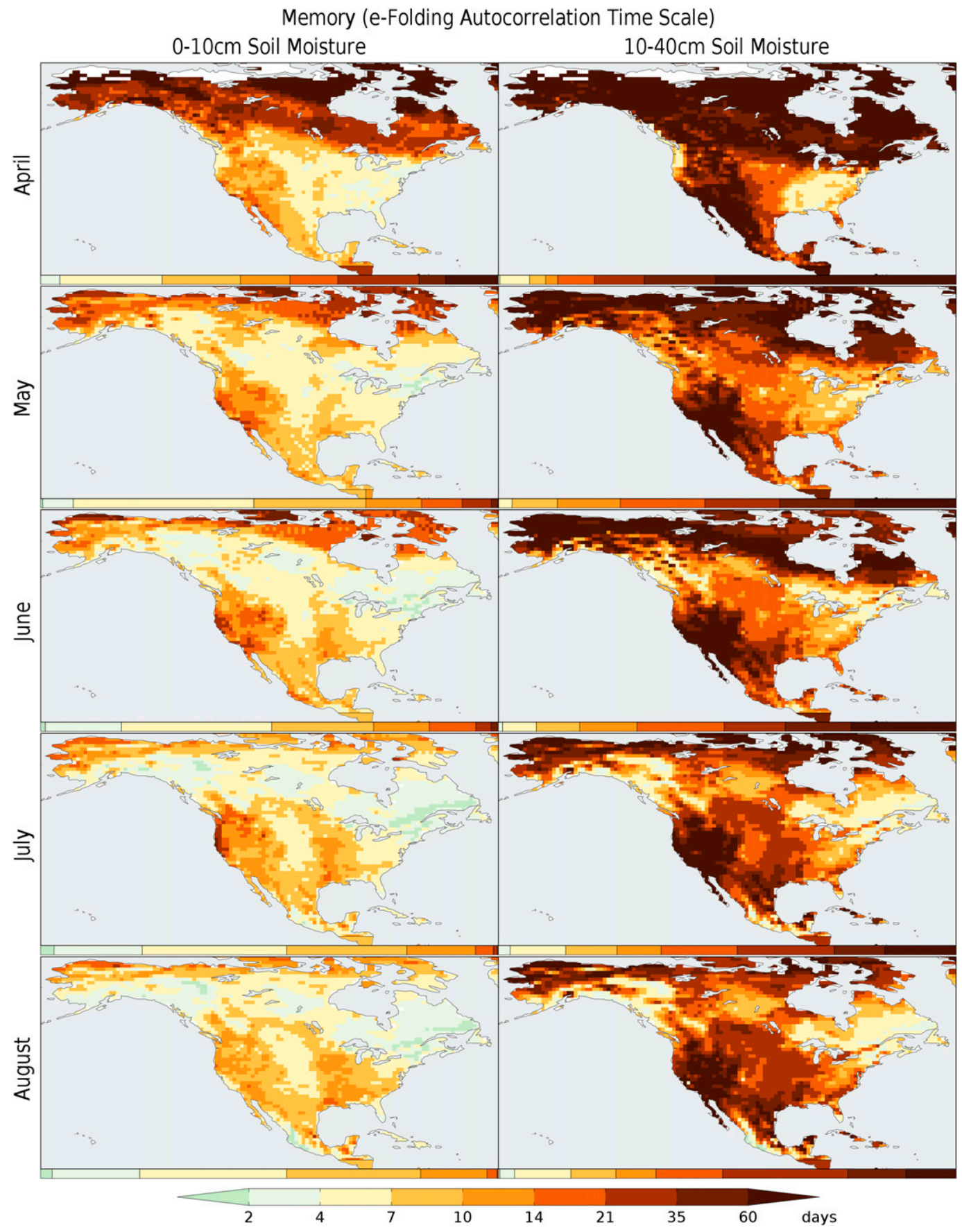

FIG. 6. As in Fig. 3, but for the memory (e-folding time of lagged autocorrelation) of volumetric soil moisture in the top two layers of the soil.

the skill of retrospective forecasts made with CFSv2? In this section we examine the skill of CFSv2 as it appears to relate to land-atmosphere coupling. First, we compare skill when land surface states are realistically initialized versus the random initialization procedure described in section 2. Next, we note the tendencies for the model to respond to locally positive and negative differences in initial soil moisture. Last, we try to attribute improvements in skill (or their absence) given realistic soil moisture initialization to the three elements of land-atmosphere coupling outlined in section 1 . To ensure a large sample size for the aggregated metrics 


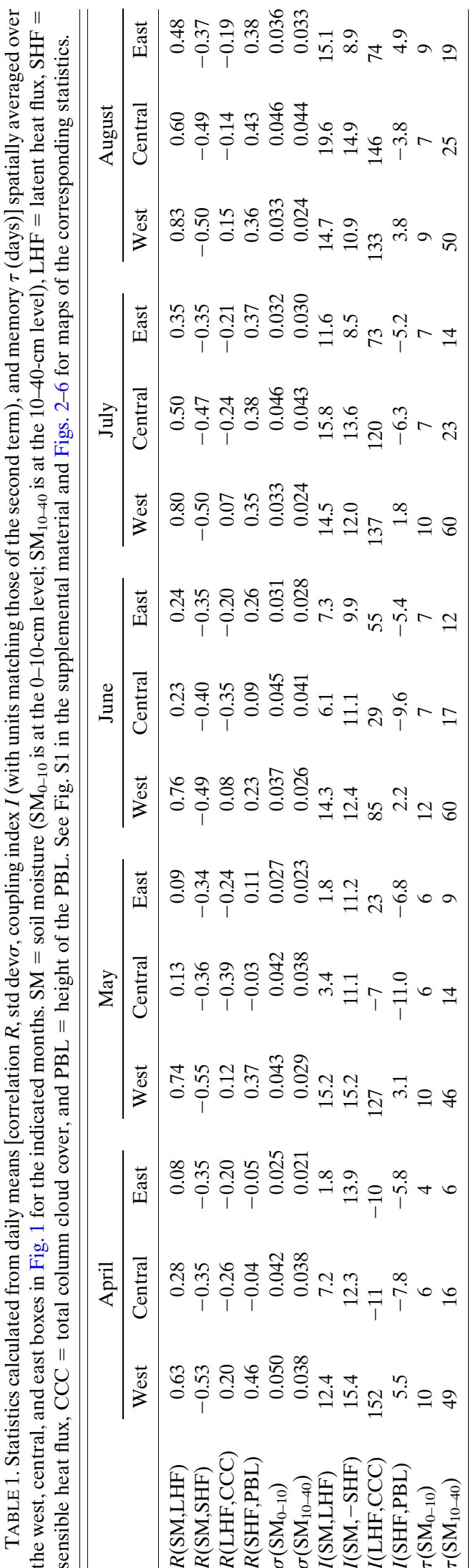

depicted in Figs. 9-12 and 14 (described in greater detail below), global analyses only are presented in this section.

\section{a. Skill evaluation}

There are significant increases in forecast skill associated with realistic initialization of the land surface state. Figure 7 shows regions that have better forecast skill in the baseline member relative to the other 27 ensemble members, measured in terms of the interannual ACC with CFSR. Regions with very small soil moisture variability (standard deviation among all simulations of top 10-cm soil moisture less than 0.005) are masked out. Significance here is defined as skill with realistic land initialization lying more than one standard deviation above the mean ACC of the 27 forecasts with randomized land initializations. Results are shown for $2-\mathrm{m}$ temperature and humidity, and the shading indicates the number of months for which the ACC of monthly means remains more than one standard deviation above the mean of the ACC for the 27 corresponding sets with randomized land initial conditions. Maps of the time scales for significant reduction in RMSE and MAE of predicted anomalies are quite similar but not shown.

Large fractions of the land area have significant improvements for at least the first month of the forecast period $(40 \%-51 \%$ of the shaded area for temperature, $35 \%-45 \%$ for humidity), and some regions show notable improvements for one season or longer, particularly in the Southern Hemisphere monsoon areas, which are in their dry seasons. Improved skill beyond one month tends to be slightly more widespread for humidity than temperature, especially for 1 June forecasts. Improved prediction skill at higher latitudes is likely due to the snow cover initialization. Improvements to precipitation (not shown) are minor and spotty in distribution, but do pass significance testing on short time scales, as shown later.

Figure 8 presents a similar analysis based on pentad averages rather than months. Because of the shorter averaging period, skill drops more quickly than in Fig. 7. Pentads 3-6 are in the range of weeks $2-4$, which are of increasing interest in the realm of subseasonal forecasting. For CFSv2, $13 \%-16 \%$ of the land surface for temperature and $\sim 14 \%$ for humidity show significantly increased skill for the third pentad or beyond. However, most of the impact of initial soil moisture is through pentads 1-3-increases of skill from pentad 4 onward cover only $5 \%-9 \%$ of the land for temperature and $4 \%-$ $7 \%$ for humidity.

Figure 9 shows the global land average (excluding areas covered with permanent ice) of the local ACC 

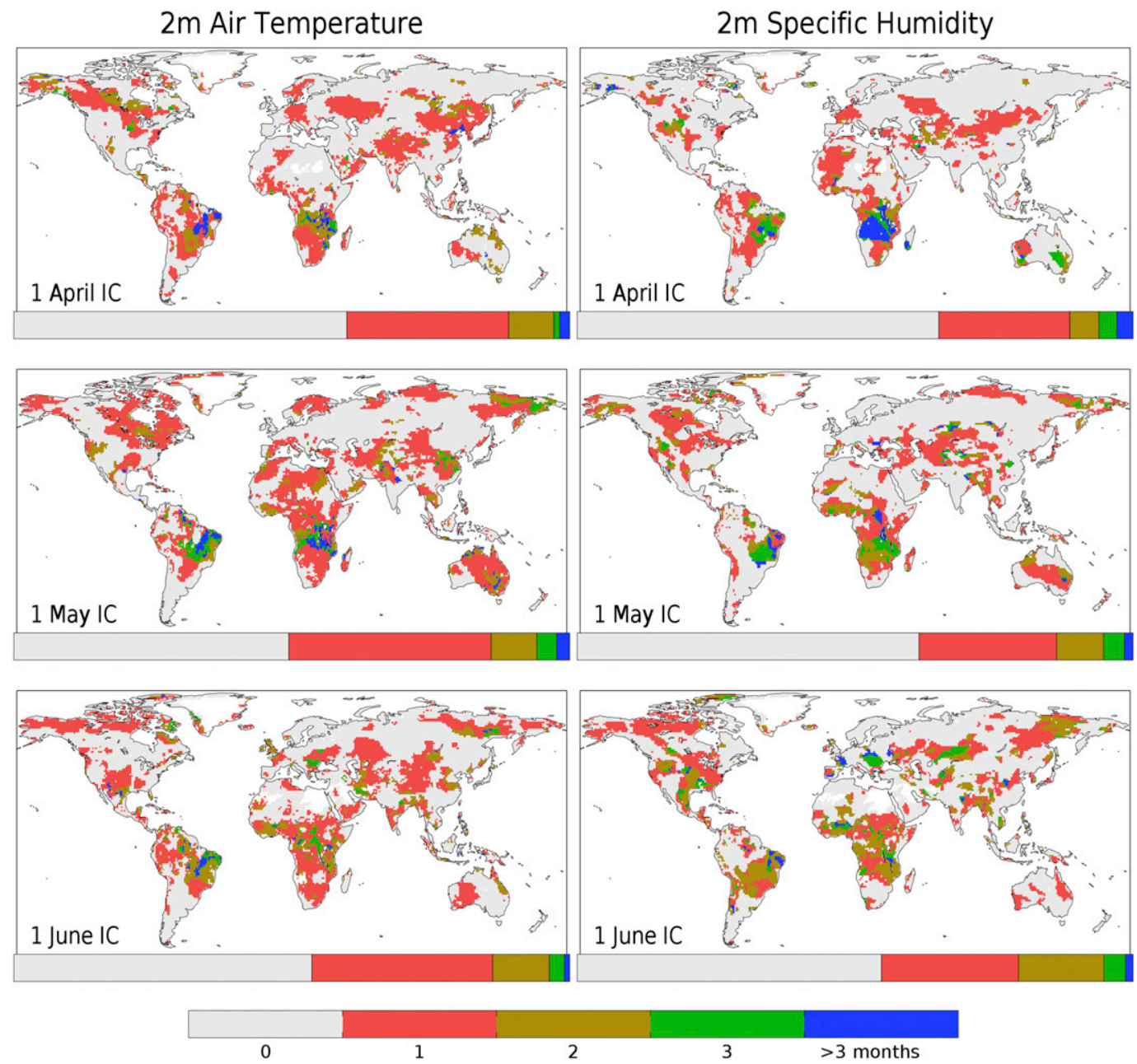

FIG. 7. Number of months where the monthly mean forecast of the indicated variables in simulations with realistic land surface initialization at the indicated dates remains significantly better than forecasts with randomized initial land states, with skill quantified by ACC. IC refers to the date of the initial conditions of the forecasts. The colored bars beneath each map reflect the fraction of land area occupied by each skill duration category.

across 28 years for forecasts started on 1 April, 1 May, and 1 June for five different variables at various lead times. This metric is an indicator of overall impact, or in a sense, the global significance of the response to land surface initialization. In each panel, the left-hand side shows results for pentad forecasts out to 35 days, and the righthand side is for monthly mean forecasts out to four months. The bar-and-whisker symbols show the mean, plus/minus one standard deviation, and range of global averages across the 27 sets of forecasts constructed from the randomized initial land conditions but with correct initial atmosphere and ocean states. The connected dots are for the set of simulations with correct/consistent land, atmosphere, and ocean initial conditions.

Starting from the left, top-layer soil moisture is obviously seen to be strongly affected by correct land surface initialization, and the globally averaged ACC remains outside the envelope of the randomly initialized sets of forecasts throughout the forecast period. The spike in skill at pentad 2 for the randomized cases is due to the correct atmospheric initialization, which introduces some skillful precipitation in the early days of the forecasts, improving soil moisture fidelity above the randomized initial states that have an ACC of zero by construction (Dirmeyer et al. 2013). Impact of accurate soil moisture initialization is reflected in global 2-m air temperature ACC for the first 15-30 days in the pentad averages (skill above the envelope of randomly initialized cases) and 1-4 months for monthly means. Similar impacts are found for 2-m humidity, but the skill in predicting daytime boundary layer evolution is more strongly improved. It is telling that this improvement is not reflected in the precipitation, 
$2 \mathrm{~m}$ Air Temperature
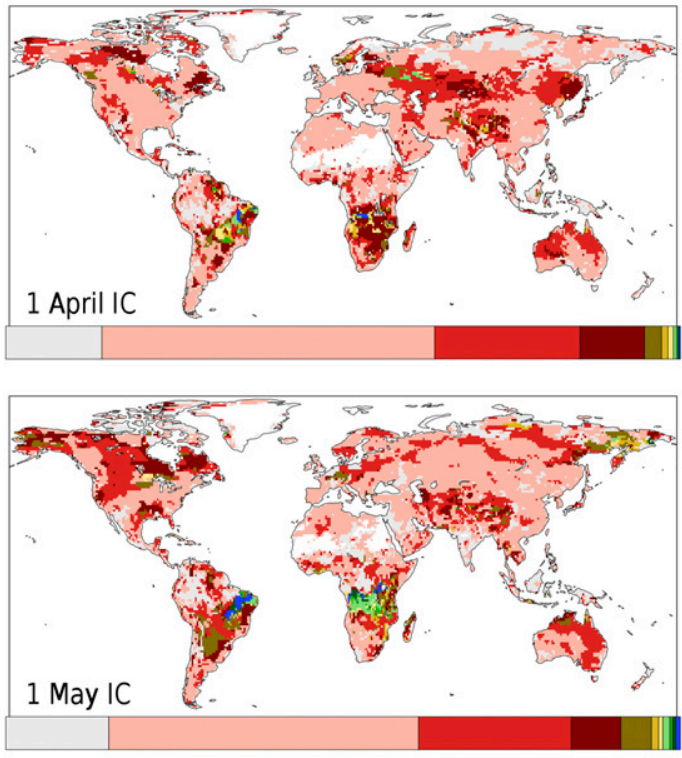

1 May IC 2m Specific Humidity
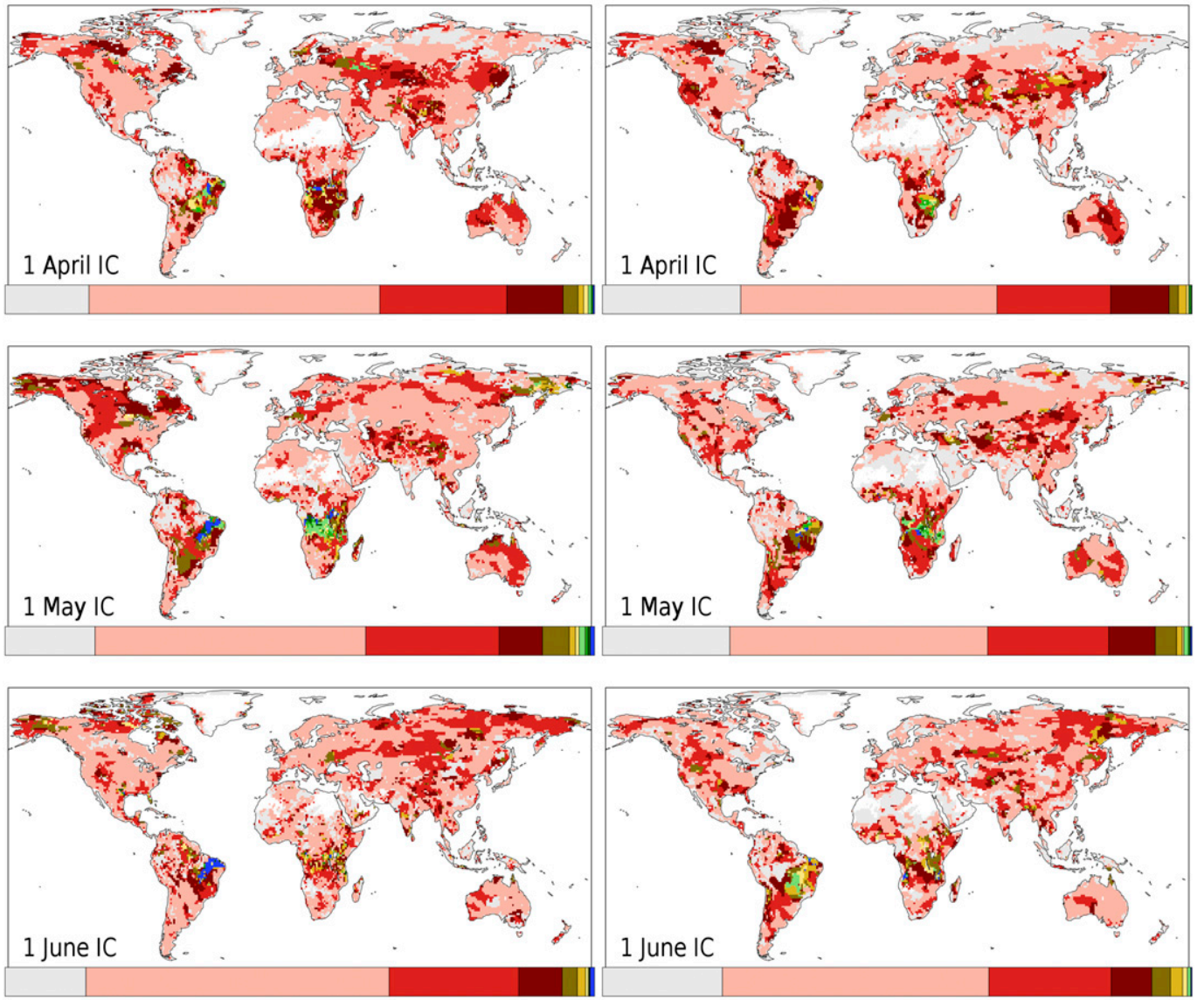

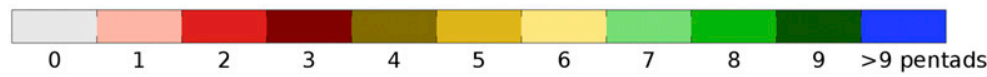

FIG. 8. As in Fig. 7, but for pentad averages.

where increased skill is seen for 5-10 days at most, and not significantly evident in the monthly means. Given the clear theoretical linkages between boundary layer growth and precipitation (e.g., Ek and Holtslag 2004; Gentine et al. 2013; Tawfik et al. 2015a,b), this suggests the model parameterizations involved in convection may not be sufficiently aided by better boundary layer simulation to improve these statistics. Other factors could also be responsible for the lack of sensitivity, such as those that exist in regions outside of convective precipitation regimes or where convection is strongly controlled by properties of the free atmosphere like midtropospheric lapse rates or moisture flux convergence.

\section{b. Asymmetric response to anomalies}

For each forecast with land surface initialization from the same day, month, and year as the atmosphere and land states, there are 27 forecasts with land surface states taken from the same day and month of other years. At each land grid point, the differences between those 27 initial states and the presumptively correct one are effectively errors in initialization, sometimes quite large. We compare those differences with subsequent errors in the forecasts of atmospheric states and properties to look for systematic atmospheric responses that suggest sensitivity of forecasts to land surface initialization errors.

We find some illuminating asymmetries in the response to the randomized land surface initialization based on the sign of the initial soil moisture errors (differences) and the sign of the subsequent meteorological variable errors. Figure 10 shows the evolution of errors in temperature when they are significantly correlated with the errors in the initial soil moisture for forecasts initialized at the beginning of June (sample size $27 \times 28=756$; plots for April and May initialization are given in the supplemental material as Figs. S12 and S13). The significances are calculated separately for positive and negative 

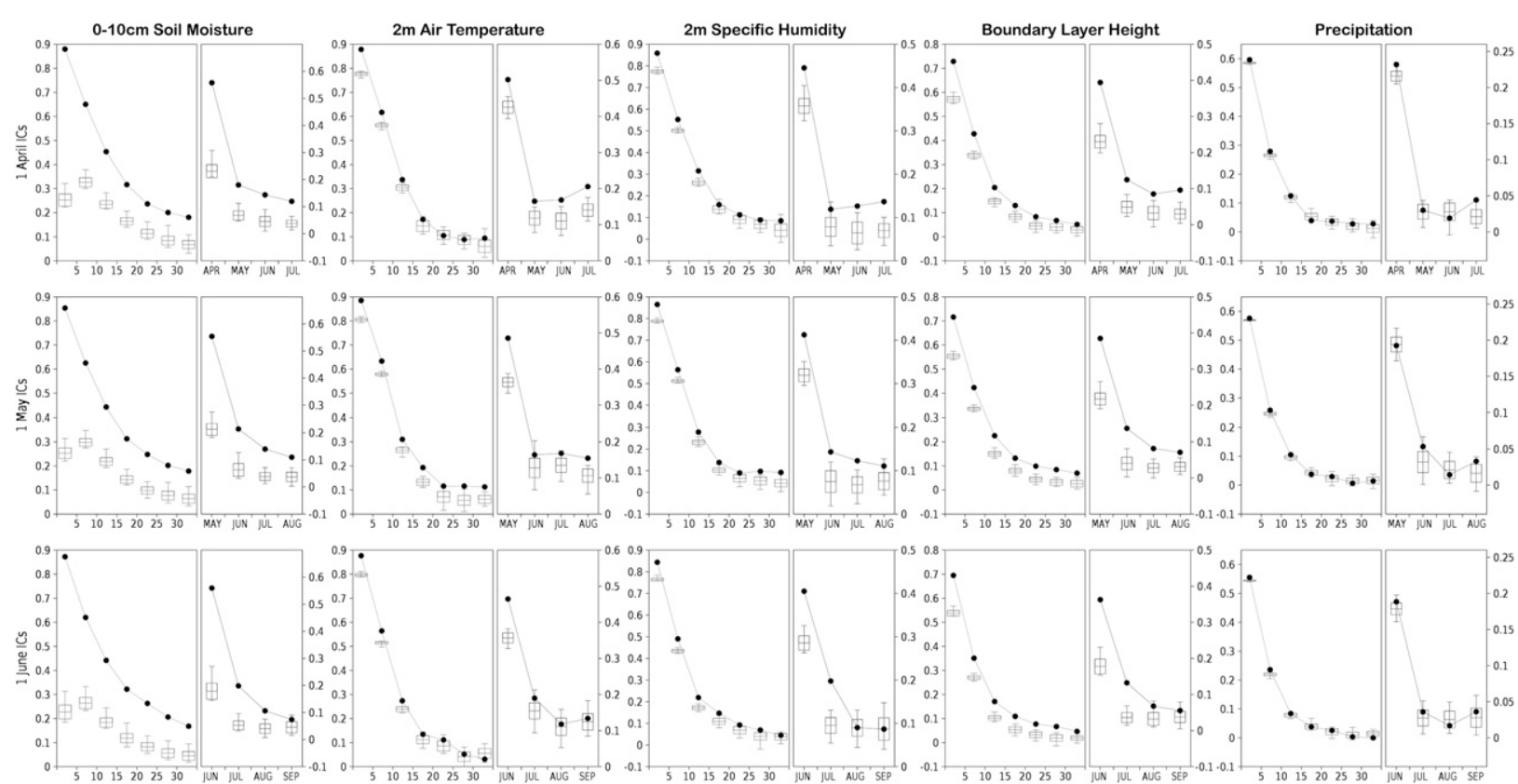

FIG. 9. For the indicated variables and initialization dates, the evolution of the global (land only) mean ACC for pentad and monthly mean forecast periods with realistic land surface initialization (connected dots) and the range of cases with randomized land initial states (boxes span plus/minus one std dev, whiskers span the entire range, and midline gives the mean).

temperature errors, shown as maps for the indicated pentads [Fig. 10 (top three plots, left)] and months [Fig. 10 (top three plots, right)] of the forecast, and the time series in Fig. 10 (bottom) shows the total percentage of land area in each category. Warm colors are where temperature and initial soil moisture errors are positively correlated and cool colors are for anticorrelations, which are more prevalent. There can be some overlap, for example, a negative correlation between soil moisture errors and temperature errors often exists for both positive and negative temperature errors (pale blue shading, dotted time series), especially early in the forecast. The pervasiveness of the areas of significant correlation and their persistence in large regions of the globe for weeks and months is a strong indicator of the importance of land surface initialization over these regions.

Figure 11 similarly shows the monthly precipitation forecast results for 1 June initialization (Fig. S14 in the supplemental material shows results for April and May initialization). Here positive correlations predominate, especially for the case where a dry initial soil moisture error leads to a negative precipitation error (yellow). However, the second-most common association is where overly wet soil moisture initial states lead to negative precipitation errors (blue). Those regions are most commonly found in arid locations and appear to be associated with the "dry soil convection advantage" regions characterized by Findell and Eltahir (2003a,b), as are green areas. It is also consistent with Findell and Eltahir (2003a,b) that red areas, where positive soil moisture errors significantly lead to positive precipitation errors, occur preferentially over the eastern United States, which was identified as having a "wet soil convection advantage." For this model, erroneously low precipitation is much more likely to result from soil moisture errors of either sign than positive precipitation errors.

\section{c. Skill attribution}

The previous subsections demonstrate the extent of positive relationships between realistic land surface initialization and forecast skill improvements in CFSv2. To understand the sources of increased skill when they occur, comparisons with the distribution of land-atmosphere coupling and soil moisture memory have been conducted. First, we group global land grid points for the forecasts of temperature and humidity with each of the three initialization dates as shown in Fig. 8 according to the number of pentads improvement in significant skill with realistic initial soil moisture. The same significance criterion is used. For each of the 10 bins (from no improvement up to 9+ pentads extension of significant skill), we find the average terrestrial coupling index for the bin at the beginning of the forecast, associating 2-m air temperature with the coupling between 0-10-cm soil moisture and surface sensible heat flux (for clarity represented here as positive for anticorrelations), 

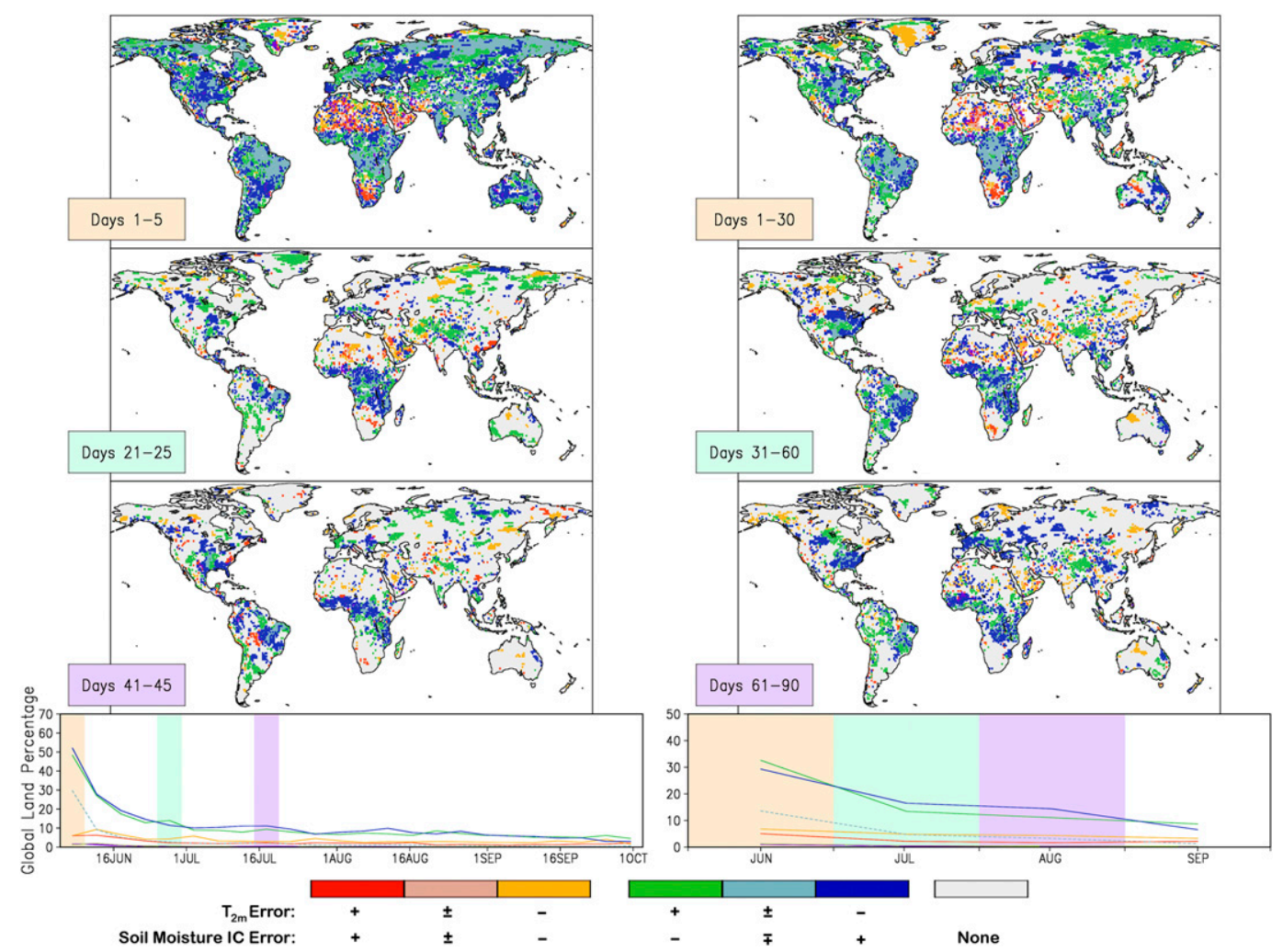

FIG. 10. Evolution of (left) pentad and (right) monthly 2-m temperature errors that are significantly correlated with 1 Jun initial soil moisture errors (comparing the randomized initial land states to realistic states). (bottom) Forecast periods in the maps are shaded in the time series of percentage of global land area in each category. Plus/ minus symbols indicate the corresponding signs of the errors; see text for details.

and 2-m specific humidity with coupling between soil moisture and latent heat flux. Grid points with soil temperatures below freezing are screened out, as soil moisture cannot vary in Noah when soil is frozen. Similarly, we determine the soil moisture memory associated with each of those same 10 bins.

The results are shown in Fig. 12. The gray plus signs are values at individual grid points; some lie beyond the range of the ordinate in these plots. Concentrating first on Fig. 12 (top), we see a very clear trend in the quartiles for the water cycle pathway (Fig. 12, right), wherein the extended skill of humidity forecasts correspond quite well to higher terrestrial coupling between soil moisture and surface latent heat flux. Such a clear trend is not evident for the energy cycle pathway (Fig. 12, left), but we find that if we correlate the latent heat coupling index with temperature and the sensible heat coupling index with humidity (not shown), the strong trends remain associated with the coupling between latent heat flux and soil moisture. This can be interpreted that the degree of landatmosphere coupling through the water cycle pathway is a determinant of prolonged forecast improvement from realistic initial soil moisture.
Figure 12 (bottom) shows the relationship between skill improvement and soil moisture memory. Note that the memory is plotted on a logarithmic time scale, as lagged autocorrelations of soil moisture behave like a first-order Markov process with exponential decay (Delworth and Manabe 1989; Robock et al. 1995; Schlosser and Milly 2002). The mean is calculated in terms of $\ln$ (time). Note that the definitions of soil moisture memory and the number of pentads of skill increase each necessarily contain arbitrary elements. For skill, the choice of significance threshold and the averaging period (5 days) are subjective choices, as is the 1/e threshold for lagged correlation to define memory. Thus, although we expect a direct relationship between the two axes, the green 1:1 line is not a hard limit for soil moisture contribution to extended skill but rather a visual guide. Indeed, we see that the increase in soil moisture memory tracks the skill increases for both temperature and humidity rather well. Furthermore, the typical memory time scale associated with multipentad increases in skillful predictions rises dramatically from April to June for both temperature and humidity (i.e., the slopes of the linear regressions increase), suggesting that the impact of soil 


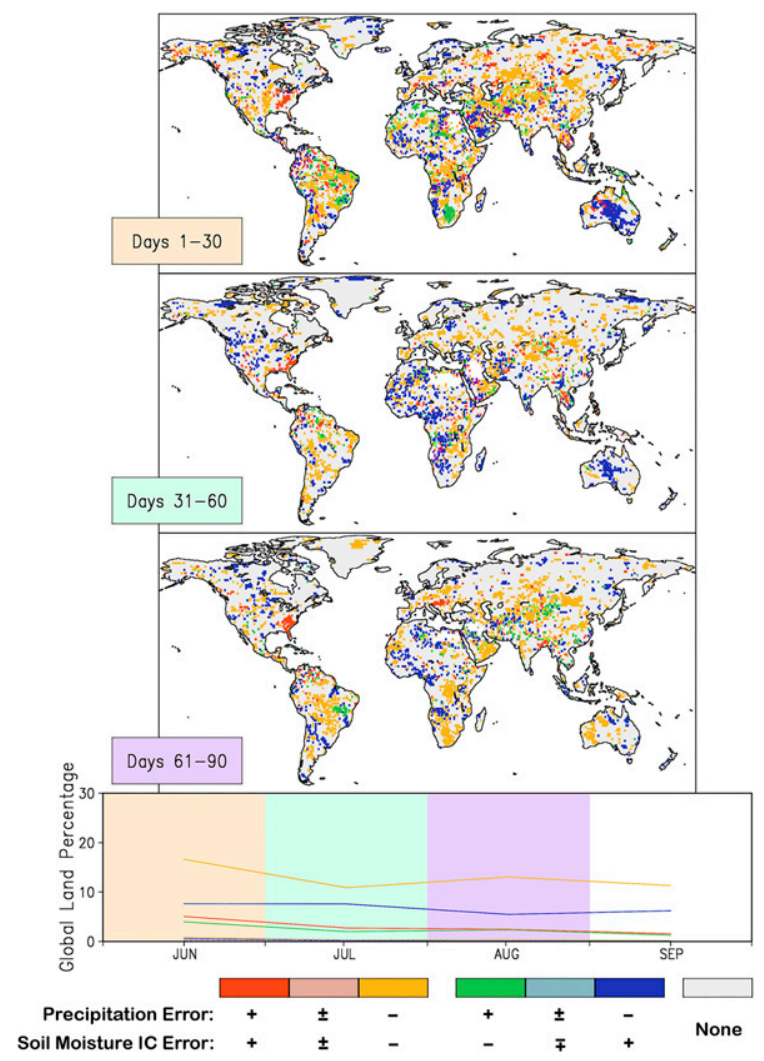

FIG. 11. As in Fig. 10 (right), but for monthly precipitation errors.

moisture memory becomes a more important factor as the boreal warm season evolves (cf. Guo et al. 2012).

Figure 13 presents maps of the ratio of forecast improvement time scale (simply the number of pentads from Fig. 8 times five) to soil moisture memory time scale. This can be interpreted as a measure of the effectiveness of soil moisture initialization in delivering forecast improvement in CFSv2. As discussed above, values greater than 1 (blue shades) should not be taken as untenable. Rather, we should look at high values of this ratio as places where potential predictability from realistic soil moisture initialization is being harvested in CFSv2. Correspondingly, lower values of this ratio are an indication that soil moisture initialization has not delivered much forecast improvement, given the memory characteristics of the model. There are several possible reasons for such a shortfall. Some are in the category of unrealized predictability from the soil moisture initialization. Perhaps the model soil moisture memory is quite different than reality, impairing results. Likewise, the soil moisture analysis from which initial states are taken may not be truly accurate or representative of the states at those locations. Alternatively, initial soil moisture may be accurate and representative, but problems in the representation of land surface processes in Noah, atmospheric processes in GFSv2, or the models' mutual coupled interactions prevent the initial soil moisture anomalies from positively affecting temperature and humidity forecasts.

On the other hand, local atmospheric conditions may not permit the existence of predictability from knowledge of land surface states-this would include cases where coupling indices are weak (note that information is not directly represented in Fig. 13). Figure 14 adds this factor back into the analysis. The abscissa contains the range between 0 and 1 of the ratio shown in Fig. 13. The ordinate shows the terrestrial coupling indices as in Fig. 12. We see clearly for the energy cycle pathway (Fig. 14, left) and somewhat more weakly for the water cycle pathway (Fig. 14, right) that there are positive trends in coupling index statistics with the ratio. June humidity forecasts are the exception. Otherwise, it appears that we may indeed interpret low values of the ratio of skill improvement to soil moisture memory as generally due to a lack of coupling strength, particularly for the energy cycle pathway. Figure 12 suggests the water cycle pathway may control the absolute duration of forecast improvement, but Fig. 14 suggests the energy cycle pathway has more effect in determining the realization of potential predictability from persistent soil moisture anomalies.

\section{Conclusions}

Land-atmosphere coupling can provide predictability and prediction skill to the atmosphere beyond deterministic weather forecast time scales because land surface states vary slowly relative to the atmosphere. In order for the land surface to deliver on the potential of increased prediction skill, there must be a demonstrated sensitivity of model atmospheric states to variations in land surface states, the magnitude of those variations must be sufficiently large relative to other sources of climate variability, and anomalies in land surface states must persist long enough for their impact on the atmosphere to become significant. Each of these three elements has been quantified in the operational NOAA/NCEP climate forecast model, CFSv2, using a large suite of seasonal retrospective forecasts initialized in April-June, wherein the effects of realistic versus randomized land surface initialization are assessed. We use these elements to describe impacts of land surface initialization on screen-level temperature and humidity, daytime boundary layer height, and precipitation. Finally, land-atmosphere coupling and soil moisture memory are compared to the changes in forecast skill to deduce the role of each element as a means by which skill improvements in land state initialization are realized in CFSv2. 

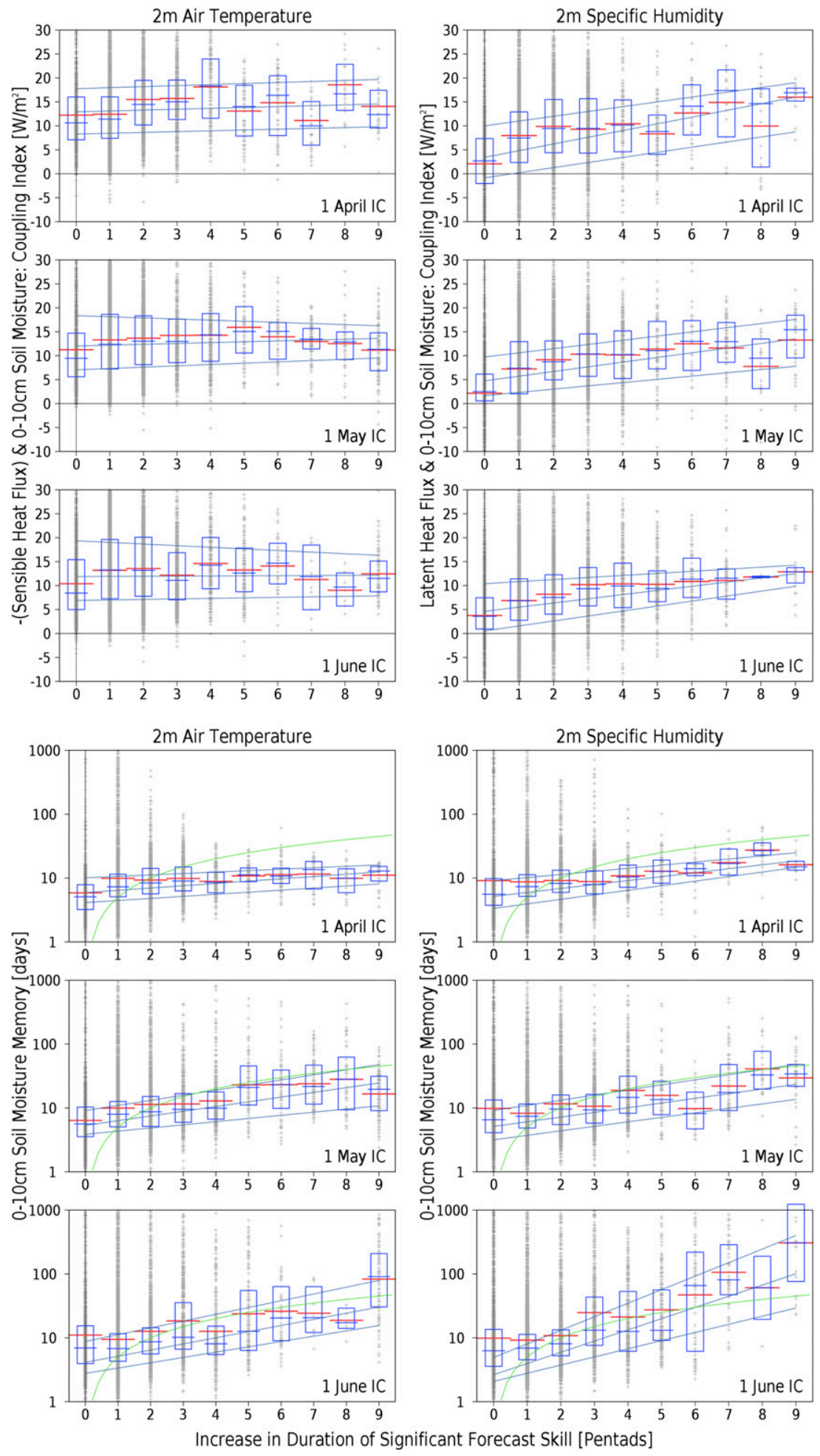

FIG. 12. (top) The distribution of terrestrial coupling indices and (bottom) soil moisture memory as a function of the increase in the duration of skillful forecasts of (left) 2-m air temperature and (right) specific humidity for ensembles with the indicated start dates for global land points that are ice free and do not have frozen soil. Red bars show mean values; blue boxes mark median, first quartile, and third quartile. Straight lines are linear regressions though the median and quartiles. The green line in the bottom denotes $X=Y$, the same time scale on both axes. 
Ratio of Pentad Forecast Improvement Time to Soil Moisture Memory $2 m$ Air Temperature
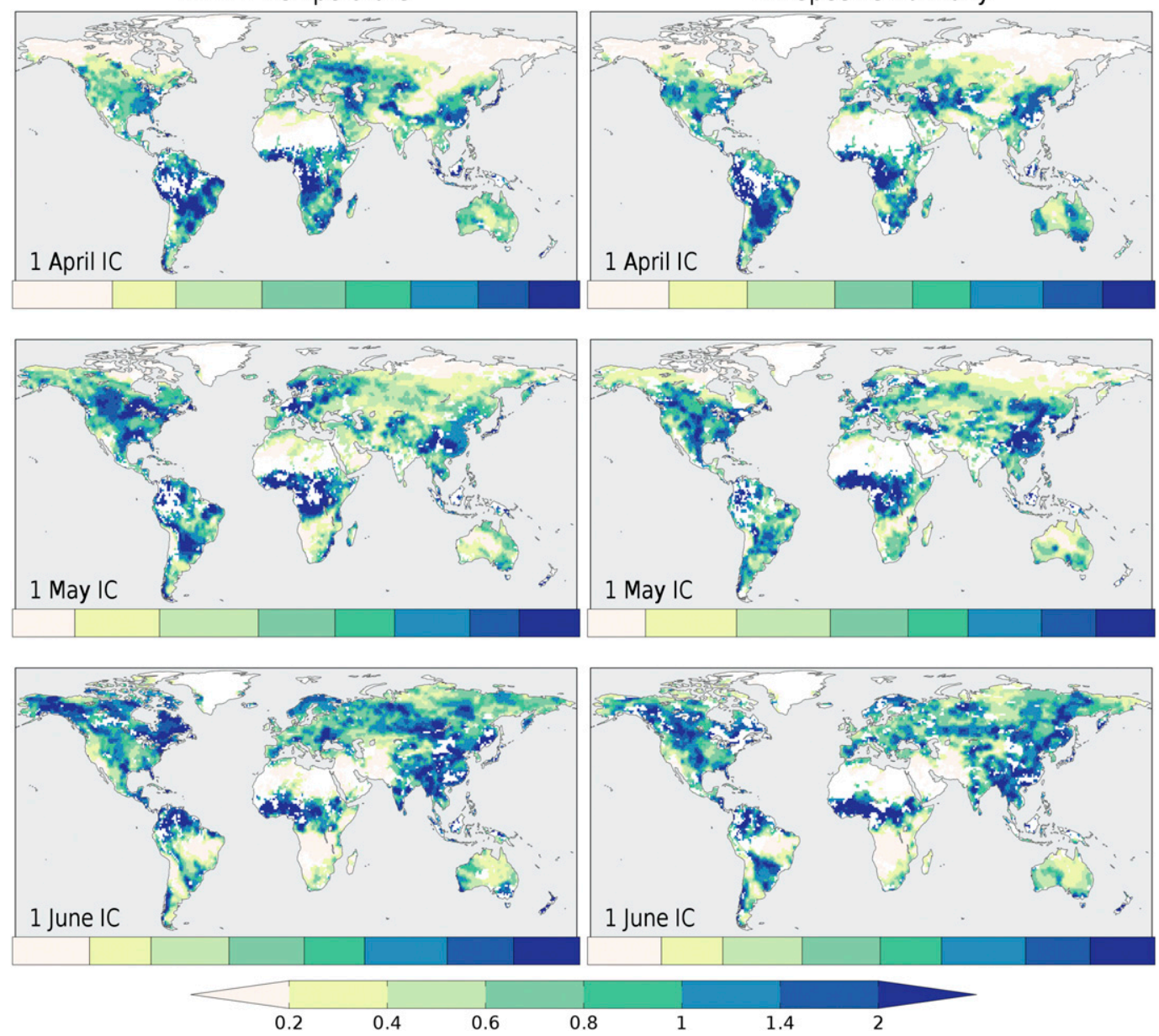

FIG. 13. The ratio of forecast improvement time scale (the number of pentads from Fig. 8 times five) to soil moisture memory time scale. Areas of very low soil moisture variability, zero soil moisture memory, or any frozen soil are masked out.

The most crucial element for improved forecast skill due to land surface initialization appears to be soil moisture memory-the degree of persistence of anomalies that allow for alterations in surface fluxes, nearsurface temperature, humidity, and boundary layer development. This is understandable, as a soil moisture anomaly should only be able to affect the atmosphere for as long as it exists. However, within the constraint of soil moisture memory, we find that land-atmosphere coupling can help convert potential predictability into prediction skill in CFSv2. We have found the signature of feedback pathways through both the energy and water cycles linking coupling strength to skill improvement for air temperature, humidity, and boundary layer growth. Impacts on precipitation, however, are only weakly positive.

Here we have portrayed the effects of land surface initialization in the context of improvements (realistic vs randomized initialization). However, there are several points to consider. One is that there is an implicit assumption that the source of land surface conditions, which is from the CFSR dataset and ultimately from the GLDAS land-only cycle with Noah driven by observationally based meteorological analyses, is perfect, or at least the best possible. In fact, there is almost certainly room for improvement, especially over regions where few actual surface observations enter the data assimilation stream. Thus, these results may not represent an upper bound for the impact of improved prediction via land surface initialization, as described in section $6 c$.

Second, the sensitivity displayed by forecasts to "improvement" of land surface states applies equally to errors in the land surface state. This is related to the first point and means that regions where we are seeing the 


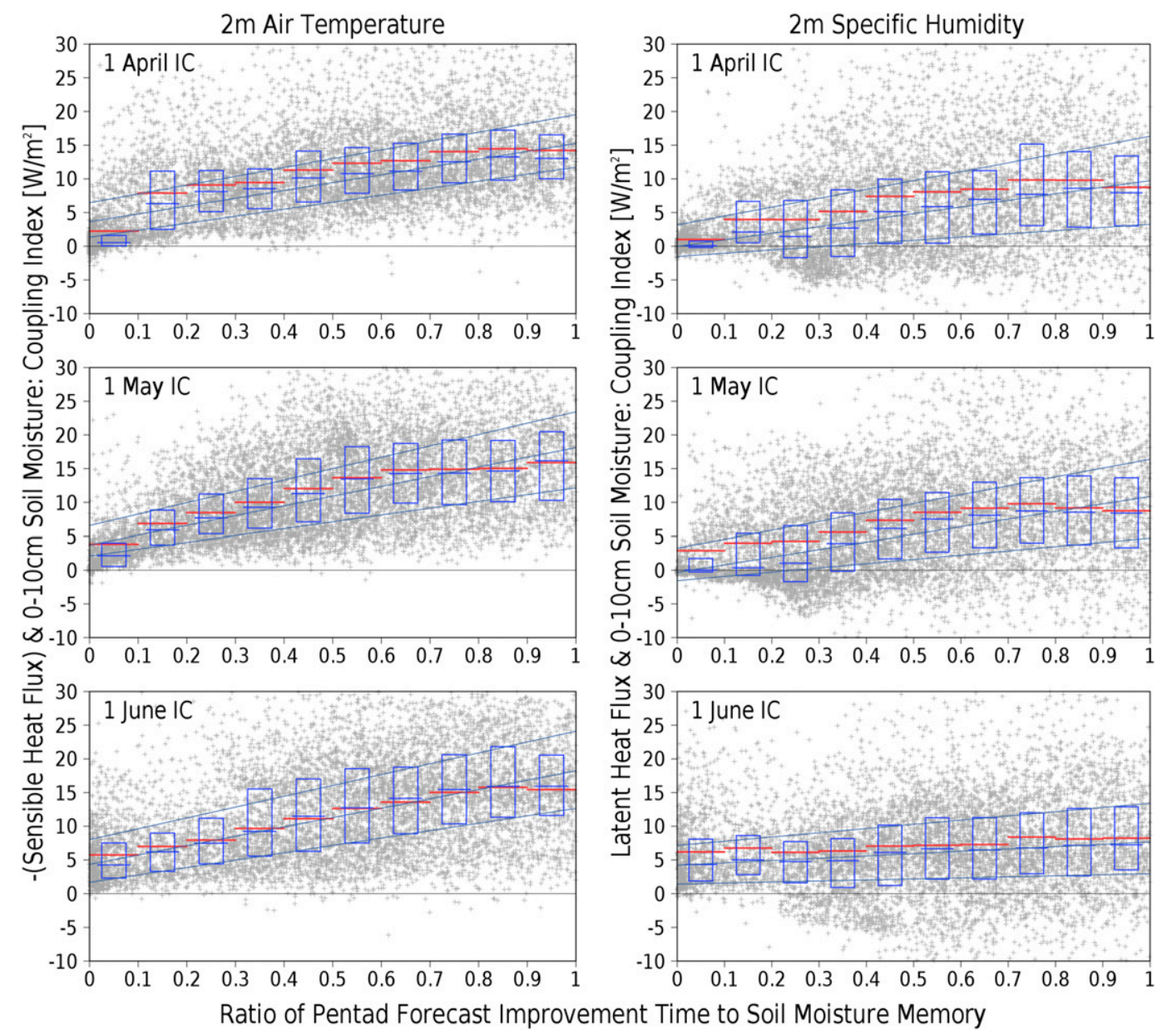

FIG. 14. As in Fig. 12 (top), but for coupling indices as a function of the ratio shown in Fig. 13. Statistics are calculated in each bin on the abscissa of width 0.1 .

greatest and longest-lasting (in terms of lead time) improvements in forecasts are likely susceptible to errors in land initialization. These may be the regions where the greatest care to ensure accurate meteorological observations, and ultimately real-time soil moisture monitoring, should be employed.

Finally, the lack of responsiveness of precipitation forecast skill to soil moisture initialization points to a possible problem in model formulation, quite likely in the convective parameterization in the atmospheric model but possibly also in other aspects of model "physics." We make this statement based on the fact that other general circulation models have demonstrated improved precipitation forecasts with more realistic soil moisture (e.g., Beljaars et al. 1996; Dirmeyer 2000; Koster et al. 2010, 2011). This may be related to problems GFSv2 exhibits in precipitation statistics (e.g., Dirmeyer 2013; Shin and Huang 2016; Lien et al. 2016) and the connection between precipitation and surface fluxes (Zhang et al.
2011). Further study at the process level, combined with the direct validation of coupling metrics with observational data, could elucidate whether there is genuine unrealized predictability of precipitation originating from the land surface.

Acknowledgments. We thank the National Monsoon Mission, Ministry of Earth Sciences, Government of India for support of this study. This work used computational resources from the Extreme Science and Engineering Discovery Environment (XSEDE) program, as supported by National Science Foundation Grant ACI1053575. Specifically, we acknowledge the Texas Advanced Computing Center (TACC) at The University of Texas at Austin for providing high-performance computing resources. Data from all simulations reside on the TACC Ranch advanced storage resource. The assistance of Lawrence Marx was crucial to the successful execution of the modeling experiments. 


\section{REFERENCES}

Accadia, C., S. Mariani, M. Casaioli, and A. Lavagnini, 2003: Sensitivity of precipitation forecast skill scores to bilinear interpolation and a simple nearest-neighbor average method on high-resolution verification grids. Wea. Forecasting, 18, 918-932, doi:10.1175/1520-0434(2003)018<0918: SOPFSS $>2.0 . \mathrm{CO} ; 2$.

Bamzai, A. S., and L. Marx, 2000: COLA AGCM simulation of the effect of anomalous spring snow over Eurasia on the Indian summer monsoon. Quart. J. Roy. Meteor. Soc., 126, 2575-2584, doi:10.1002/qj.49712656811.

Barker, H. W., R. Pincus, and J.-J. Morcrette, 2002: The Monte Carlo independent column approximation: Application within largescale models. Extended Abstracts, GCSS-ARM Workshop on the Representation of Cloud Systems in Large-Scale Models, Kananaskis, AB, Canada, GEWEX, 1-10.

Beljaars, A. C., P. Viterbo, M. J. Miller, and A. K. Betts, 1996: The anomalous rainfall over the United States during July 1993: Sensitivity to land surface parameterization and soil moisture anomalies. Mon. Wea. Rev., 124, 362-383, doi:10.1175/ 1520-0493(1996)124<0362:TAROTU > 2.0.CO;2.

Berg, A., K. Findell, B. R. Lintner, P. Gentine, and C. Kerr, 2013: Precipitation sensitivity to surface heat fluxes over North America in reanalysis and model data. J. Hydrometeor., 14, 722-743, doi:10.1175/JHM-D-12-0111.1.

, and Coauthors, 2015: Interannual coupling between summertime surface temperature and precipitation over land: Processes and implications for climate change. J. Climate, 28, 1308-1328, doi:10.1175/JCLI-D-14-00324.1.

Best, M., A. Lock, J. Santanello, G. Svensson, and B. Holtslag, 2013: A new community experiment to understand land-atmosphere coupling processes. GEWEX News, Vol. 23, No. 2, International GEWEX Project Office, Silver Spring, MD, 3-5.

Betts, A. K., 2009: Land-surface-atmosphere coupling in observations and models. J. Adv. Model. Earth Syst., 1, doi:10.3894/ JAMES.2009.1.4.

— , J. H. Ball, A. C. M. Beljaars, M. J. Miller, and P. A. Viterbo, 1996: The land surface-atmosphere interaction: A review based on observational and global modeling perspectives. J. Geophys. Res., 101, 7209-7225, doi:10.1029/95JD02135.

Betts, R. A., 2000: Offset of the potential carbon sink from boreal forestation by decreases in surface albedo. Nature, 408, 187190, doi:10.1038/35041545.

_ , P. D. Falloon, K. K. Goldewijk, and N. Ramankutty, 2007: Biogeophysical effects of land use on climate: Model simulations of radiative forcing and large-scale temperature change. Agric. For. Meteor., 142, 216-223, doi:10.1016/j.agrformet.2006.08.021.

Cavalieri, D. J., C. Parkinson, P. Gloersen, and H. J. Zwally, 1996: Sea ice concentrations from Nimbus-7 SMMR and DMSP SSM/I-SSMIS passive microwave data, version 1 (updated yearly). National Snow and Ice Data Center Distributed Active Archive Center, accessed 13 October 2016, doi:10.5067/ 8GQ8LZQVLOVL.

,,--- , and - , 2007: Sea ice concentrations from Nimbus-7 SMMR and DMSP SSM/I passive microwave data, version 1. Subset used: 1978-1996 (updated yearly), National Snow and Ice Data Center Distributed Active Archive Center, accessed 13 October 2016, doi:10.5067/8GQ8LZQVL0VL.

Chun, H.-Y., and J.-J. Baik, 1998: Momentum flux by thermally induced internal gravity wave and its approximation for largescale models. J. Atmos. Sci., 55, 3299-3310, doi:10.1175/ 1520-0469(1998)055<3299:MFBTII>2.0.CO;2.
Clough, S. A., M. W. Shephard, E. J. Mlawer, J. S. Delamere, M. J. Iacono, K. Cady-Pereira, S. Boukabara, and P. D. Brown, 2005: Atmospheric radiative transfer modeling: A summary of the AER codes. J. Quant. Spectrosc. Radiat. Transfer, 91, 233244, doi:10.1016/j.jqsrt.2004.05.058.

Delworth, T., and S. Manabe, 1989: The influence of soil wetness on near-surface atmospheric variability. J. Climate, 2, 1447-1462, doi:10.1175/1520-0442(1989)002<1447:TIOSWO>2.0.CO;2.

Dirmeyer, P. A., 2000: Using a global soil wetness data set to improve seasonal climate simulation. J. Climate, 13, 2900-2922, doi:10.1175/1520-0442(2000)013<2900:UAGSWD>2.0.CO;2.

_ 2006: The hydrologic feedback pathway for land-climate coupling. J. Hydrometeor., 7, 857-867, doi:10.1175/JHM526.1.

_ 2011: The terrestrial segment of soil moisture-climate coupling. Geophys. Res. Lett., 38, L16702, doi:10.1029/ 2011 GL048268.

_ 2013: Characteristics of the water cycle and land-atmosphere interactions from a comprehensive reforecast and reanalysis data set: CFSv2. Climate Dyn., 41, 1083-1097, doi:10.1007/ s00382-013-1866-x.

— , and J. Shukla, 1993: Observational and modeling studies of the influence of soil moisture anomalies on atmospheric circulation. Prediction of Interannual Climate Variations, J. Shukla, Ed., NATO ASI Series I, Vol. 6, Springer, 1-23, doi:10.1007/978-3-642-76960-3_1.

—_, and M. Zhao, 2004: Flux replacement as a method to diagnose coupled land-atmosphere model feedback. J. Hydrometeor., 5, 1034-1048, doi:10.1175/JHM-384.1.

— , and A. Tawfik, 2014: Validation of CFSv2 model behaviorLand-atmosphere interactions and the hydrologic cycle. Climate Prediction $S \& T$ Digest, 38th Climate Diagnostics and Prediction Workshop Special Issue, NOAA/NWS, Silver Spring, MD, 75-79. [Available online at https://issuu.com/ climatesti/docs/38cdpwdigest.]

, and S. Halder, 2016: Sensitivity of numerical weather forecasts to initial soil moisture variations in CFSv2. Wea. Forecasting, 31, 1973-1983, doi:10.1175/WAF-D-16-0049.1.

_ A. J. Dolman, and N. Sato, 1999: The Global Soil Wetness Project: A pilot project for global land surface modeling and validation. Bull. Amer. Meteor. Soc., 80, 851-878, doi:10.1175/ 1520-0477(1999)080<0851:TPPOTG $>2.0 . C O ; 2$.

—, X. Gao, M. Zhao, Z. Guo, T. Oki, and N. Hanasaki, 2006: The Second Global Soil Wetness Project (GSWP-2): Multimodel analysis and implications for our perception of the land surface. Bull. Amer. Meteor. Soc., 87, 1381-1397, doi:10.1175/ BAMS-87-10-1381.

—, C. A. Schlosser, and K. L. Brubaker, 2009: Precipitation, recycling and land memory: An integrated analysis. J. Hydrometeor., 10, 278-288, doi:10.1175/2008JHM1016.1.

—_, and Coauthors, 2012: Simulating the hydrologic diurnal cycle in global climate models: Resolution versus parameterization. Climate Dyn., 39, 399-418, doi:10.1007/ s00382-011-1127-9.

—, S. Kumar, M. J. Fennessy, E. L. Altshuler, T. DelSole, Z. Guo, B. Cash, and D. Straus, 2013: Model estimates of landdriven predictability in a changing climate from CCSM4. J. Climate, 26, 8495-8512, doi:10.1175/JCLI-D-13-00029.1.

_ C. Peters-Lidard, and G. Balsamo, 2015: Land-atmosphere interactions and the water cycle. Seamless Prediction of the Earth System: From Minutes to Months, G. Brunet, S. Jones, and P.M. Ruti, Eds., WMO-1156, World Meteorological Organization, 145-154. [Available online at http://library.wmo. int/pmb_ged/wmo_1156_en.pdf.] 
- - and Coauthors, 2016: Confronting weather and climate models with observational data from soil moisture networks over the United States. J. Hydrometeor., 17, 1049-1067, doi:10.1175/JHM-D-15-0196.1.

Ek, M. B., and A. A. M. Holtslag, 2004: Influence of soil moisture on boundary layer cloud development. J. Hydrometeor., 5, 86-99, doi:10.1175/1525-7541(2004)005<0086:IOSMOB > 2.0.CO;2.

_, K. E. Mitchell, Y. Lin, E. Rogers, P. Grunmann, V. Koren, G. Gayno, and J. D. Tarpley, 2003: Implementation of Noah land surface model advances in the National Centers for Environmental Prediction operational mesoscale Eta model. J. Geophys. Res., 108, 8851, doi:10.1029/2002JD003296.

Ferguson, C. R., and E. F. Wood, 2011: Observed land-atmosphere coupling from satellite remote sensing and reanalysis. J. Hydrometeor., 12, 1221-1254, doi:10.1175/2011JHM1380.1.

_ - — , and R. K. Vinukollu, 2012: A global intercomparison of modeled and observed land-atmosphere coupling. J. Hydrometeor., 13, 749-784, doi:10.1175/JHM-D-11-0119.1.

Findell, K. L., and E. A. B. Eltahir, 2003a: Atmospheric controls on soil moisture-boundary layer interactions. Part I: Framework development. J. Hydrometeor., 4, 552-569, doi:10.1175/ 1525-7541(2003)004<0552:ACOSML>2.0.CO;2.

$\longrightarrow$, and $\longrightarrow$, 2003b: Atmospheric controls on soil moistureboundary layer interactions. Part II: Feedbacks within the continental United States. J. Hydrometeor., 4, 570-583, doi:10.1175/1525-7541(2003)004<0570:ACOSML>2.0.CO;2.

Fischer, E. M., S. I. Seneviratne, P. L. Vidale, D. Lüthi, and C. Schär, 2007: Soil moisture-atmosphere interactions during the 2003 European summer heat wave. J. Climate, 20, 50815099, doi:10.1175/JCLI4288.1.

Ford, T. W., A. D. Rapp, S. M. Quiring, and J. Blake, 2015: Soil moisture-precipitation coupling: Observations from the Oklahoma Mesonet and underlying physical mechanisms. Hydrol. Earth Syst. Sci., 19, 3617-3631, doi:10.5194/ hess-19-3617-2015.

Gentine, P., A. A. M. Holtslag, F. D'Andrea, and M. Ek, 2013: Surface and atmospheric controls on the onset of moist convection over land. J. Hydrometeor., 14, 1443-1462, doi:10.1175/JHM-D-12-0137.1.

Griffies, S. M., M. J. Harrison, R. C. Pacanowski, and A. Rosati, 2004: A technical guide to MOM4. GFDL Ocean Group Tech. Rep. 5, 342 pp. [Available online at https://www.gfdl.noaa.gov/ bibliography/related_files/smg0301.pdf.]

Grumbine, R. W., 1996: Automated passive microwave sea ice concentration analysis at NCEP. NCEP OMB Tech. Note 120, 13 pp. [Available online at http://polar.ncep.noaa.gov/mmab/ papers/tn120/ssmi120.pdf.]

Guo, Z., and Coauthors, 2006: GLACE: The Global LandAtmosphere Coupling Experiment. Part II: Analysis. J. Hydrometeor., 7, 611-625, doi:10.1175/JHM511.1.

— P. A. Dirmeyer, T. DelSole, and R. D. Koster, 2012: Rebound in atmospheric predictability and the role of the land surface. J. Climate, 25, 4744-4749, doi:10.1175/JCLI-D-11-00651.1.

Helfrich, S. R., D. McNamara, B. H. Ramsay, T. Baldwin, and T. Kasheta, 2007: Enhancements to, and forthcoming developments in the Interactive Multisensor Snow and Ice Mapping System (IMS). Hydrol. Processes, 21, 1576-1586, doi:10.1002/hyp.6720.

Hirsch, A. L., J. Kala, A. J. Pitman, C. Carouge, J. P. Evans, V. Haverd, and D. Mocko, 2014: Impact of land surface initialization approach on subseasonal forecast skill: A regional analysis in the Southern Hemisphere. J. Hydrometeor., 15, 300-319, doi:10.1175/JHM-D-13-05.1.
Iacono, M. J., E. J. Mlawer, S. A. Clough, and J.-J. Morcrette, 2000: Impact of an improved longwave radiation model, RRTM, on the energy budget and thermodynamic properties of the NCAR Community Climate Model, CCM3. J. Geophys. Res., 105, 14 873-14 890, doi:10.1029/2000JD900091.

Kopp, T. J., and R. B. Kiess, 1996: The Air Force Global Weather Central snow analysis model. Preprints, 15th Conf. on Weather Analysis and Forecasting, Norfolk, VA, Amer. Meteor. Soc., 220-222.

Koster, R. D., and M. J. Suarez, 2001: Soil moisture memory in climate models. J. Hydrometeor., 2, 558-570, doi:10.1175/ 1525-7541(2001)002<0558:SMMICM > 2.0.CO;2.

, — and M. Heiser, 2000: Variance and predictability of precipitation at seasonal-to-interannual timescales. J. Hydrometeor., 1, 26-46, doi:10.1175/1525-7541(2000)001<0026: VAPOPA $>2.0 . \mathrm{CO} ; 2$.

- and Coauthors, 2004: Regions of strong coupling between soil moisture and precipitation. Science, 305, 1138-1140, doi:10.1126/science.1100217.

and Coauthors, 2006: GLACE: The Global LandAtmosphere Coupling Experiment. Part I: Overview. J. Hydrometeor., 7, 590-610, doi:10.1175/JHM510.1.

$\longrightarrow$, S. D. Schubert, and M. J. Suarez, 2009: Analyzing the concurrence of meteorological droughts and warm periods, with implications for the determination of evaporative regime. J. Climate, 22, 3331-3341, doi:10.1175/2008JCLI2718.1.

- , and Coauthors, 2010: Contribution of land surface initialization to subseasonal forecast skill: First results from a multimodel experiment. Geophys. Res. Lett., 37, L02402, doi:10.1029/2009GL041677.

, and Coauthors, 2011: The second phase of the Global LandAtmosphere Coupling Experiment: Soil moisture contributions to subseasonal forecast skill. J. Hydrometeor., 12, 805-822, doi:10.1175/2011JHM1365.1.

Lien, G.-Y., E. Kalnay, T. Miyoshi, and G. J. Huffman, 2016: Statistical properties of global precipitation in the NCEP GFS model and TMPA observations for data assimilation. Mon. Wea. Rev., 144, 663-679, doi:10.1175/ MWR-D-15-0150.1.

Lorenz, R., A. J. Pitman, A. L. Hirsch, and J. Srbinovsky, 2015: Intraseasonal versus interannual measures of land-atmosphere coupling strength in a global climate model: GLACE-1 versus GLACE-CMIP5 experiments in ACCESS1.3b. J. Hydrometeor., 16, 2276-2295, doi:10.1175/JHM-D-14-0206.1.

, and Coauthors, 2016: Influence of land-atmosphere feedbacks on temperature and precipitation extremes in the GLACE-CMIP5 ensemble.J. Geophys. Res. Atmos., 121, 607623, doi:10.1002/2015JD024053.

Meng, J., R. Yang, H. Wei, M. Ek, G. Giyno, P. Xie, and K. Mitchell, 2012: The land surface analysis in the NCEP Climate Forecast System Reanalysis. J. Hydrometeor., 13, 1621-1630, doi:10.1175/JHM-D-11-090.1.

Mlawer, E. J., S. J. Taubman, P. D. Brown, M. J. Iacono, and S. A. Clough, 1997: Radiative transfer for inhomogeneous atmosphere: RRTM, a validated correlated- $k$ model for the longwave. J. Geophys. Res., 102, 16663-16683, doi:10.1029/ 97JD00237.

Namias, J., 1959: Persistence of mid-tropospheric circulations between adjacent months and seasons. The Atmosphere and the Sea in Motion, B. Bolin, Ed., Rockefeller University Press, 240-248.

1960: Factors in the initiation, perpetuation and termination of drought. IAHS Publ., 51, 81-94. 
Peters-Lidard, C. D., and Coauthors, 2007: High performance Earth system modeling with NASA/GSFC's Land Information System. Innovations Syst. Software Eng., 3, 157-165, doi:10.1007/s11334-007-0028-x.

Pincus, R., H. W. Barker, and J.-J. Morcrette, 2003: A fast, flexible, approximate technique for computing radiative transfer in inhomogeneous cloud fields. J. Geophys. Res., 108, 4376, doi:10.1029/2002JD003322.

Reynolds, R. W., T. M. Smith, C. Liu, D. B. Chelton, K. S. Casey, and M. G. Schlax, 2007: Daily high-resolution blended analyses for sea surface temperature. J. Climate, 20, 5473-5496, doi:10.1175/2007JCLI1824.1.

Robock, A., K. Ya. Vinnikov, C. A. Schlosser, N. A. Speranskaya, and Y. Xue, 1995: Use of midlatitude soil moisture and meteorological observations to validate soil moisture simulations with biosphere and bucket models. J. Climate, 8, 15-35, doi:10.1175/1520-0442(1995)008<0015: UOMSMA $>2.0 . \mathrm{CO} ; 2$.

Roundy, J. K., and E. F. Wood, 2015: The attribution of landatmosphere interactions on the seasonal predictability of drought. J. Hydrometeor., 16, 793-810, doi:10.1175/ JHM-D-14-0121.1.

, C. R. Ferguson, and E. F. Wood, 2014: Impact of landatmospheric coupling in CFSv2 on drought prediction. Climate Dyn., 43, 421-434, doi:10.1007/s00382-013-1982-7.

Saha, S., and Coauthors, 2010: The NCEP Climate Forecast System Reanalysis. Bull. Amer. Meteor. Soc., 91, 1015-1057, doi:10.1175/2010BAMS3001.1.

— , and Coauthors, 2014: The NCEP Climate Forecast System version 2. J. Climate, 27, 2185-2208, doi:10.1175/ JCLI-D-12-00823.1.

Santanello, J. A., C. D. Peters-Lidard, and S. V. Kumar, 2011: Diagnosing the sensitivity of local land-atmosphere coupling via the soil moisture-boundary layer interaction. J. Hydrometeor., 12, 766-786, doi:10.1175/JHM-D-10-05014.1.

,$- \ldots$, A. Kennedy, and S. Kumar, 2013: Diagnosing the nature of land-atmosphere coupling: A case study of dry/wet extremes in the U.S. southern Great Plains. J. Hydrometeor., 14, 1373-1400, doi:10.1175/JHM-D-12-0127.1.

Schlosser, C. A., and P. C. D. Milly, 2002: A model-based investigation of soil moisture predictability and associated climate predictability. J. Hydrometeor., 3, 483-501, doi:10.1175/ 1525-7541(2002)003<0483:AMBIOS > 2.0.CO;2.

Seneviratne, S. I., and Coauthors, 2013: Impact of soil moistureclimate feedbacks on CMIP5 projections: First results from the GLACE-CMIP5 experiment. Geophys. Res. Lett., 40, 5212-5217, doi:10.1002/grl.50956.
Shin, C.-S., and B. Huang, 2016: Slow and fast annual cycles of the Asian summer monsoon in the NCEP CFSv2. Climate Dyn., 47, 529-553, doi:10.1007/s00382-015-2854-0.

Song, H.-J., C. R. Ferguson, and J. K. Roundy, 2016: Landatmosphere coupling at the Southern Great Plains Atmospheric Radiation Measurement (ARM) field site and its role in anomalous afternoon peak precipitation. J. Hydrometeor., 17, 541-556, doi:10.1175/JHM-D-15-0045.1.

Sud, Y. C., J. Shukla, and Y. Mintz, 1988: Influence of land surface roughness on atmospheric circulation and precipitation: A sensitivity study with a general circulation model. J. Appl. Meteor., 27, 1036-1054, doi:10.1175/1520-0450(1988)027<1036: IOLSRO $>2.0 . \mathrm{CO} ; 2$

Sun, R., S. Moorthi, and C. R. Mechoso, 2010: Simulation of low clouds in the southeast Pacific by the NCEP GFS: Sensitivity to vertical mixing. Atmos. Chem. Phys., 10, 12 261-12272, doi:10.5194/acp-10-12261-2010.

Tawfik, A. B., P. A. Dirmeyer, and J. A. Santanello, 2015a: The heated condensation framework. Part I: Description and Southern Great Plains case study. J. Hydrometeor., 16, 19291945, doi:10.1175/JHM-D-14-0117.1.

$\longrightarrow, \ldots$, and 2015b: The heated condensation framework. Part II: Climatological behavior of convective initiation and land-atmosphere coupling over the continental United States. J. Hydrometeor., 16, 1946-1961, doi:10.1175/JHM-D-14-0118.1.

Tebaldi, C., and R. Knutti, 2007: The use of the multi-model ensemble in probabilistic climate projections. Philos. Trans. Roy. Soc. London, 365A, 2053-2075, doi:10.1098/rsta.2007.2076.

van den Hurk, B., M. Best, P. A. Dirmeyer, A. J. Pitman, J. Polcher, and J. Santanello, 2011: Over a decade of GLASS has accelerated land surface model development. Bull. Amer. Meteor. Soc., 92, 1593-1600, doi:10.1175/BAMS-D-11-00007.1.

Xie, P., and P. A. Arkin, 1997: Global precipitation: A 17-year monthly analysis based on gauge observations, satellite estimates, and numerical model outputs. Bull. Amer. Meteor. Soc., 78, 2539-2558, doi:10.1175/1520-0477(1997)078<2539:GPAYMA > 2.0.CO;2.

_, M. Chen, A. Yatagai, T. Hayasaka, Y. Fukushima, and S. Yang, 2007: A gauge-based analysis of daily precipitation over East Asia. J. Hydrometeor., 8, 607-626, doi:10.1175/JHM583.1.

Zhang, L., P. A. Dirmeyer, J. Wei, Z. Guo, and C.-H. Lu, 2011: Landatmosphere coupling strength in the Global Forecast System. J. Hydrometeor., 12, 147-156, doi:10.1175/2010JHM1319.1.

Zhang, Y., and S. A. Klein, 2013: Factors controlling the vertical extent of fair-weather non-precipitating shallow cumulus: Investigation of diurnal-cycle observations collected at the ARM Southern Great Plains site. J. Atmos. Sci., 70, 12971315, doi:10.1175/JAS-D-12-0131.1. 